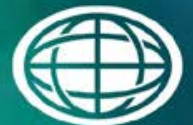

Savannah River

National Laboratory ${ }^{\mathrm{m}}$

\title{
Defining and Characterizing Sample Representativeness for DWPF Melter Feed Samples
}

E.P. Shine

M.R. Poirier

October 2013

SRNL-STI-2013-00544 
SRNL-STI-2013-00544

Revision 0

\section{DISCLAIMER}

This work was prepared under an agreement with and funded by the U.S. Government. Neither the U.S. Government or its employees, nor any of its contractors, subcontractors or their employees, makes any express or implied:

1. warranty or assumes any legal liability for the accuracy, completeness, or for the use or results of such use of any information, product, or process disclosed; or

2. representation that such use or results of such use would not infringe privately owned rights; or

3. endorsement or recommendation of any specifically identified commercial product, process, or service.

Any views and opinions of authors expressed in this work do not necessarily state or reflect those of the United States Government, or its contractors, or subcontractors.

Printed in the United States of America

Prepared for

U.S. Department of Energy 


\section{Defining and Characterizing Sample Representativeness for DWPF Melter Feed Samples}

E.P. Shine

M.R. Poirier

October 2013 


\section{REVIEWS AND APPROVALS}

\section{AUTHORS:}

E.P. Shine, Applied Computational Engineering and Statistics

Date

M.R. Poirier, Advanced Characterization and Process Technology

Date

\section{TECHNICAL REVIEW:}

S.H. Reboul, Advanced Characterization and Process Technology

Date

T.B. Edwards, Applied Computational Engineering and Statistics

Date

\section{APPROVAL:}

C.C. Herman, SRNL Hanford Program Manager

Date

E\&CP Research Programs

S. L. Marra, Manager

Date

Environmental \& Chemical Process Technology Research Programs

M.K. Harris, Manager

Date

Computational Sciences 


\section{Executive Summary}

Representative sampling is important throughout the Defense Waste Processing Facility (DWPF) process, and the demonstrated success of the DWPF process to achieve glass product quality over the past two decades is a direct result of the quality of information obtained from the process. The objective of this report was to present sampling methods that the Savannah River Site (SRS) used to qualify waste being dispositioned at the DWPF. The goal was to emphasize the methodology, not a list of outcomes from those studies. This methodology includes proven methods for taking representative samples, the use of controlled analytical methods, and data interpretation and reporting that considers the uncertainty of all error sources. Numerous sampling studies were conducted during the development of the DWPF process and still continue to be performed in order to evaluate options for process improvement. Study designs were based on use of statistical tools applicable to the determination of uncertainties associated with the data needs. Successful designs are apt to be repeated, so this report chose only to include prototypic case studies that typify the characteristics of frequently used designs.

Case studies have been presented for studying in-tank homogeneity, evaluating the suitability of sampler systems, determining factors that affect mixing and sampling, comparing the final waste glass product chemical composition and durability to that of the glass pour stream sample and other samples from process vessels, and assessing the uniformity of the chemical composition in the waste glass product. Many of these studies efficiently addressed more than one of these areas of concern associated with demonstrating sample representativeness and provide examples of statistical tools in use for DWPF.

The time when many of these designs were implemented was in an age when the sampling ideas of Pierre Gy were not as widespread as they are today. Nonetheless, the engineers and statisticians used carefully thought out designs that systematically and economically provided plans for data collection from the DWPF process. Key shared features of the sampling designs used at DWPF and the Gy sampling methodology were the specification of a standard for sample representativeness, an investigation that produced data from the process to study the sampling function, and a decision framework used to assess whether the specification was met based on the data. Without going into detail with regard to the seven errors identified by Pierre Gy, as excellent summaries are readily available such as Pitard [1989] and Smith [2001], SRS engineers understood, for example, that samplers can be biased (Gy's extraction error), and developed plans to mitigate those biases. Experiments that compared installed samplers with more representative samples obtained directly from the tank may not have resulted in systematically partitioning sampling errors into the now well-known error categories of Gy, but did provide overall information on the suitability of sampling systems.

Most of the designs in this report are related to the DWPF vessels, not the large SRS Tank Farm tanks. Samples from the DWPF Slurry Mix Evaporator (SME), which contains the feed to the DWPF melter, are characterized using standardized analytical methods with known uncertainty. The analytical error is combined with the established error from sampling and processing in DWPF to determine the melter feed composition. This composition is used with the known uncertainty of the models in the Product Composition Control System (PCCS) to ensure that the wasteform that is produced is comfortably within the acceptable processing and product performance region. Having the advantage of many years of 
processing that meets the waste glass product acceptance criteria, the DWPF process has provided a considerable amount of data about itself in addition to the data from many special studies. Demonstrating representative sampling directly from the large Tank Farm tanks is a difficult, if not unsolvable enterprise due to limited accessibility. However, the consistency and the adequacy of sampling and mixing at SRS could at least be studied under the controlled process conditions based on samples discussed by Ray and others [2012a] in Waste Form Qualification Report (WQR) Volume 2 and the transfers from Tanks 40H and $51 \mathrm{H}$ to the Sludge Receipt and Adjustment Tank (SRAT) within DWPF. It is important to realize that the need for sample representativeness becomes more stringent as the material gets closer to the melter, and the tanks within DWPF have been studied extensively to meet those needs. 


\section{TABLE OF CONTENTS}

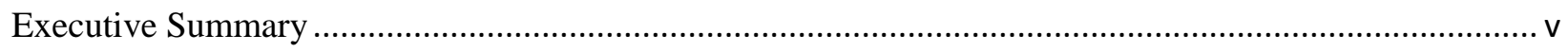

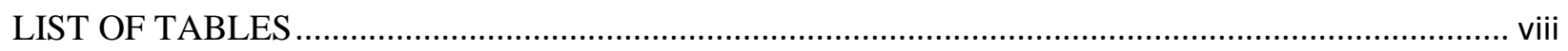

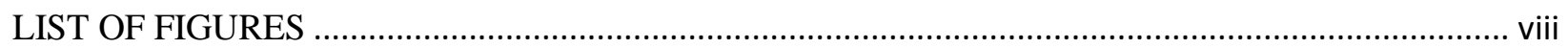

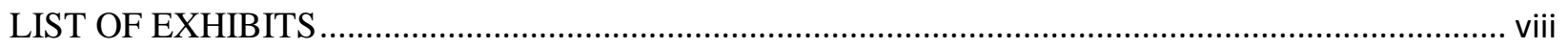

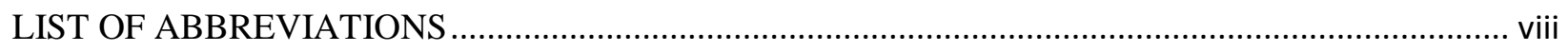

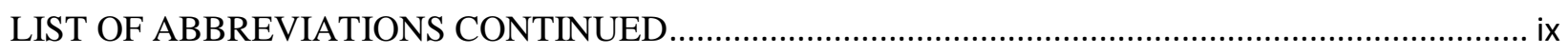

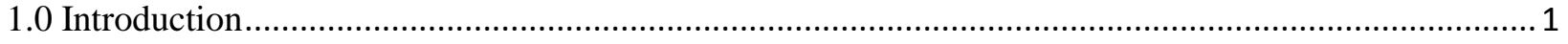

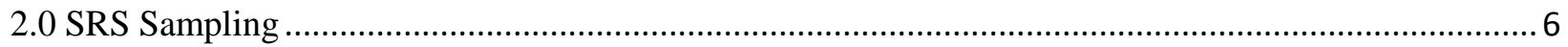

3.0 Sampling and the Pierre Gy Sampling Technology ….................................................................. 8

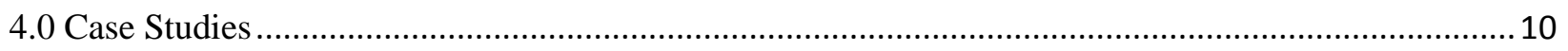

4.1 Tank Homogeneity and Liquid Sampler Testing ....................................................................... 11

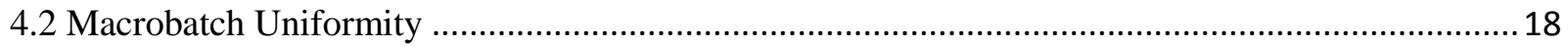

4.3 Waste Glass Chemical Composition and Uniformity …........................................................... 22

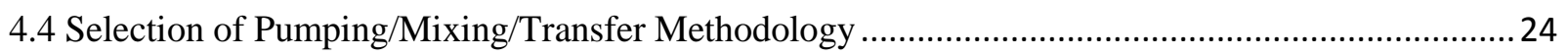

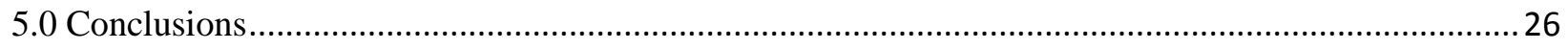

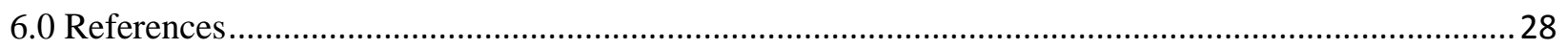

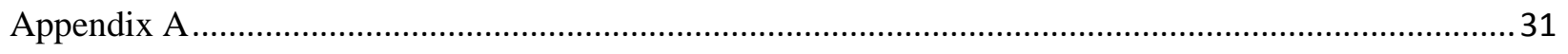




\section{LIST OF TABLES}

Table 1. Components of Variance for the Radionuclide Concentrations from MB1a ................................20

Table 2. Components of Variance for the Radionuclide Concentrations from MB1b...............................20

Table A1. Components of Variance for SRAT Receipt from MB2 …................................................. 31

\section{LIST OF FIGURES}

Figure 1. Arrangement of Coliwasa Grab Samples in the SME

\section{LIST OF EXHIBITS}

Exhibit A1. Components of Variance for SRAT Receipt Batches from MB1b 33

Exhibit A2. Components of Variance for Aluminum and Iron from MB1b....

\section{LIST OF ABBREVIATIONS}

$\begin{array}{ll}\text { Coliwasa } & \text { Composite Liquid Waste Sampler } \\ \text { CSSX } & \text { Caustic Side Solvent Extraction } \\ \text { DWPF } & \text { Defense Waste Processing Facility } \\ \text { HM } & \text { H-modified Process } \\ \text { ISDP } & \text { Integrated Salt Disposition Process } \\ \text { LWO } & \text { Liquid Waste Organization } \\ \text { MB } & \text { Macrobatch } \\ \text { MCU } & \text { Modular Caustic Unit } \\ \text { MFT } & \text { Melter Feed Tank } \\ \text { MST } & \text { Monosodium Titanate } \\ \text { NIST } & \text { National Institute of Standards and Technology } \\ \text { PCT } & \text { Product Consistency Test } \\ \text { PHEF } & \text { Precipitate Hydrolysis Experimental Facility }\end{array}$




\section{LIST OF ABBREVIATIONS CONTINUED}

$\begin{array}{ll}\text { PRBT } & \text { Precipitate Reactor Bottom Tank } \\ \text { PUREX } & \text { Plutonium Uranium Extraction } \\ \text { SB } & \text { Sludge Batch } \\ \text { SME } & \text { Slurry Mix Evaporator } \\ \text { SPF } & \text { Saltstone Production Facility } \\ \text { SRAT } & \text { Sludge Receipt and Adjustment Tank } \\ \text { SRNL } & \text { Savannah River National Laboratory } \\ \text { SRS } & \text { Savannah River Site } \\ \text { TNX } & \text { Technical Annex } \\ \text { wt \% } & \text { Weight Percent } \\ \text { \%RSD } & \text { Relative Standard Deviation expressed as a Percent } \\ \text { WAPS } & \text { Waste Acceptance Product Specification } \\ \text { WQR } & \text { Waste Form Qualification Report }\end{array}$


SRNL-STI-2013-00544

Revision 0

This Page Left Intentionally Blank 
SRNL-STI-2013-00544

Revision 0

\subsection{Introduction}

The Savannah River Site (SRS) stores radioactive liquid waste in its two Tank Farms (F-Area Tank Farm and H-Area Tank Farm). It is currently treating and disposing of the waste with three processes, the Integrated Salt Disposition Process (ISDP), the Defense Waste Processing Facility (DWPF), and the Saltstone Production Facility (SPF).

The ISDP process treats the liquid fraction of the waste by adding monosodium titanate (MST) to sorb ${ }^{90} \mathrm{Sr}$ and select actinides (e.g., Pu). The MST and entrained sludge are removed from the liquid with a crossflow filter. The rejected solids are concentrated and washed to reduce the dissolved solids concentration before being transferred to the DWPF for vitrification. The filtrate is processed through a modular caustic side solvent extraction (CSSX) unit (MCU) to remove the ${ }^{137} \mathrm{Cs}$ from the liquid stream. The cesium is stripped from the solvent and transferred to the DWPF for vitrification. The decontaminated liquid is transferred to the SPF where it is turned into a grout for disposal. The ISDP started radioactive operations in 2008.

The sludge portion of the waste is washed in a waste tank to reduce the concentration of dissolved solids, and transferred to the DWPF to be vitrified. At the DWPF, the sludge is mixed with nitric and formic acid in the Sludge Receipt and Adjustment Tank (SRAT). It is transferred to the Slurry Mix Evaporator (SME), where it is mixed with glass frit and concentrated to produce the melter feed. The SME product is transferred to the Melter Feed Tank (MFT), and subsequently fed to the melter. The DWPF started radioactive operations in 1996.

Sampling is an important part of the radioactive liquid waste storage and treatment process at SRS. Cercy and Others [2013] provide a concise description of the DWPF flowsheet and key sample points. Prior to processing a liquid stream (or salt batch), the salt batch must be qualified. The qualification process consists of collecting samples from the salt batch that will be processed. The samples are analyzed to determine the chemical and radiochemical composition of the waste stream. In addition, subsamples are contacted with MST and filtered. The filtrate is analyzed to determine the anticipated ${ }^{90} \mathrm{Sr}$ and $\mathrm{Pu}$ removal. The filtrate is then contacted with solvent, scrub solution, and strip solution to determine the anticipated cesium removal from the salt solution and the cesium concentration in the strip solution.

The batch qualification program depends on the samples collected being representative of the contents of the tank. To prepare for the first ISDP batch, the SRS Liquid Waste Organization (LWO) added 444,000 gallons of Tank $23 \mathrm{H}$ salt solution to 721,000 gallons of salt solution in Tank $49 \mathrm{H}$. They mixed these solutions with a single quad-volute slurry pump. The analysis of the ISDP qualification sample showed the liquid to be well mixed, as reported by Nash, Peters, and Fink [2008].

In addition to the ISDP feed qualification samples, the SRS Tank Farms collect samples for the tank corrosion control program. The SRS Tank Farm waste tanks are constructed of carbon steel. To reduce/prevent corrosion, corrosion inhibitors $\left(\mathrm{NaOH}\right.$ and $\left.\mathrm{NaNO}_{2}\right)$ are added to the liquid in the tanks. The amount of each inhibitor addition depends on the current composition of the tank. Samples are 
collected periodically, and analyzed for anions and free hydroxide. Based on these analyses, additional $\mathrm{NaOH}$ and/or $\mathrm{NaNO}_{2}$ are added to the tank.

Prior to vitrifying a sludge batch, the sludge batch must be qualified. The qualification process currently consists of collecting a three liter sample from the sludge batch that will be processed. The method of collection was determined over several years and has been shown to be consistent when samples are taken under controlled conditions (Ray [2012a]). The samples are analyzed by Savannah River National Laboratory (SRNL) to determine the chemical and radiochemical composition of the waste stream. Use of demonstrated analytical methods, requisite quality assurance measures, and replicate subsample analyses provide a sound means for acquiring data with known analytical quality. The subsamples are processed through the key DWPF steps to verify that an acceptable glass will be produced from the sludge. Collecting a representative sample of the sludge is more difficult that collecting a representative sample of the liquid. The sludge particles will settle which can happen very slowly for high aluminum sludge from the H-modified (HM) process or can happen rapidly for high iron sludge from the Plutonium Uranium Extraction (Purex) process. In addition, a concentrated sludge waste can behave as a Bingham plastic fluid, whereby part of the tank is well mixed and the remainder is not mixed at all. However, SRNL conducted testing to determine the zone of influence or effective cleaning radius of slurry pumps, which is a function of pump nozzle diameter, pump nozzle discharge velocity, slurry density and slurry yield stress. Based on this testing and the expected properties of the sludge in waste tanks, SRS installs a sufficient number of pumps in sludge tanks to ensure the sludge can be mixed, mobilized, and removed from the tanks.

The SRS typically uses four slurry pumps to mix sludge tanks prior to sampling. The use of four pumps is based on testing and waste tank demonstrations during the development and startup of the DWPF.

During the Tank 16H demonstration, SRS installed standard slurry pumps in Tank $16 \mathrm{H}$. Testing showed that two pumps did not effectively slurry all of the sludge. Three pumps slurried all of the sludge except for a $450 \mathrm{ft}^{2}$ pile of sludge under Riser 3. Comly [1979] concluded that three or four standard pumps would be required for hydraulic cleaning of a waste tank, depending on the tank type.

During the demonstration of sludge washing in Tank 42H, Ator [1984] reported that periscopic inspections showed good mixing was achieved with four standard slurry pumps operating in a full tank.

The technical data summary for in-tank sludge processing recommended a minimum of five standard slurry pumps or three quad volute pumps for mixing sludge storage tanks (i.e., Tank $40 \mathrm{H}$ and Tank $51 \mathrm{H}$ ). If sludge blending or obtaining a homogeneous sludge composition is desired, four quad volute pumps were recommended by Motyka [1984]. These recommendations have been maintained since the start-up of DWPF with a few occasions of three quad volume pumps used for mixing before transfer to the DWPF but not for extended periods.

The major contributors to the chemical composition of the DWPF feed are as follows.

- Sludge consists of insoluble solids containing most of the long-lived radionuclides in the waste. It is the major source for $\mathrm{Al}, \mathrm{Ca}, \mathrm{Fe}, \mathrm{Mn}, \mathrm{Ni}$, and $\mathrm{U}$ and contributes $\mathrm{Na}$ and $\mathrm{Si}$ to the feed. 
- Salt Effluents consist of MST/sludge solids and cesium strip effluent. This is the major source for Ti and contributes Na to the feed.

- Frit is a premelted granular borosilicate glass that is tailored to combine with the sludge and salt effluent wastes to form an acceptable glass product. It is the major source for $\mathrm{B}$ and $\mathrm{Li}$ and contributes $\mathrm{Na}$ and $\mathrm{Si}$ to the feed.

It may be helpful to distinguish among various "batches" of feed material. The following descriptions are taken from Ray and others [2012b].

- $\quad$ Salt feed batches are salt process effluents prepared in the Tank Farm.

- Sludge batches are portions of sludge that are prepared in the Tank Farm in 300,000 to 700,000 gallon batches. A particular sludge batch (SB) is identified as SB followed by its number.

- A macrobatch consists of salt feed, sludge, and frit. A macrobatch contains a portion of sludge during periods of relatively constant glass composition, so a macrobatch can be smaller than a sludge batch if process changes such as a significant change to frit composition occur, or contain multiple sludge batches if the glass composition remains relatively constant.

- A process batch is a portion of a macrobatch that resides in a DWPF vessel. A small portion of a process batch, a heel, will be left behind after a transfer. Consequently, a process batch changes composition as it is transferred from one vessel to another as it gains one heel and relinquishes another. A process batch may take on a special name from the vessel in which it resides.

o A SME batch is a process batch that consists of the material transferred to it from the SRAT, material left behind in the heel from the previous SME batch, and the addition of the frit. The Waste Acceptance Product Specification (WAPS) from the Office of Environmental Management [1996] must be met for each SME batch before it is transferred to the melter feed tank.

o A MFT batch is a process batch that consists of the material transferred to it from the SME plus the heel from the previous MFT batch. The contents of the MFT are transferred to the melter.

After the feed is melted, it is poured into product containers which are subsequently decontaminated, closed, and placed into an interim storage facility to await eventual shipment to a federal repository. Approximately five to eight product canisters can be produced from a single MFT batch. The waste glass product cannot be reworked or remediated, so the melter feed material must be determined to be acceptable prior to melting. The WAPS specifies that the DWPF controls the durability of the glass product as measured by the Product Consistency Test (PCT), and the DWPF achieves this by controlling 
the process parameters which affect the results of the PCT in the last feed preparation vessel, the SME. The pour stream is also sampled in order to characterize the glass.

The primary parameter that can be varied in DWPF is the chemical composition of the feed so it is the parameter that is tightly monitored and controlled. Samples of feed from each process batch are taken from the SME and are analyzed by the DWPF laboratory to determine the glass process and performance properties and the reportable elements. The slurry samples are converted to glass in preparation for analysis, since vitrification allows use of stable glass standards that closely resemble the DWPF glass for laboratory quality control purposes. The glass standards are specified by SRNL, procured in accordance with the DWPF QA program, and are frequently analyzed as check standards. The results from these standards are used to identify and correct biases or other negative trends, if any. Solution standards similar to dissolved glass are also utilized as instrument calibration standards and as checks on the analytical methods. Whenever possible, instrument calibration standards for analytical methods are materials which are traceable to National Institute of Standards and Technology (NIST) or to other nationally recognized sources. Standard samples are also analyzed frequently to monitor short- and longterm variances.

The analytical procedures used by DWPF are based on SRNL developed methods. The DWPF Analytical Services Group adapted these methods and prepared procedures for their use in the DWPF laboratory. The DWPF laboratory's quality assurance and control program ensures the accuracy of the analytical values reported and controls the precision so that it is at least within expected values. The laboratory program includes the following elements: personnel, equipment and instrumentation, and procedures and systems.

The chemical composition measurements from a minimum of four SME process samples are input to the DWPF's Product Composition Control System (PCCS), a statistical process control system for monitoring SME batches and for supporting acceptability decisions at this production hold-point for DWPF. The PCCS strategy is to blend and then monitor the composition of the feed slurry in the SME, since the SME is the first control point at which all of the necessary constituents are present and also the last control point at which any change to the constituents can be effected.

The SME acceptability determination for DWPF process control is described by Edwards (2006). SME acceptability involves meeting process and product constraints such as viscosity, liquidus temperature, and durability, after uncertainties associated with the SME samples and property-composition models have been taken into account. The product quality constraints derive from WAPS (Office of Environmental Management [1996]).

In addition to the acceptability determination, the SME results are used for WAPS reporting of the glass composition. The analyses from all of the process batches in the macrobatch are averaged, and the average composition is corrected for any significant biases, so that the errors in the reported composition are treated as random variations. The composition of the canistered waste forms from the macrobatch is reported as this average value along with the calculated standard deviations in the DWPF Production Records. 
During the development of the waste form compliance strategy for the DWPF, it was recognized that there were multiple sources of error in the measurement of the chemical composition. The specific identified sources of error in WQR Volume 2 (Ray 2012a) include process batch uniformity, slurry sampling, the analytical system, macrobatch uniformity, and error in calculation of the average macrobatch composition. Bias and random errors were considered for each of the error sources, which allowed overall uncertainty to be calculated while also identifying the largest source of error in the process. For a more thorough explanation of the methods used in estimating uncertainty/error in DWPF data, see WQR Volume 2 (Ray 2012a). The property projections from PCCS consider the analytical source of error as discussed above and the uncertainty in the prediction model as discussed in Edwards (2006).

This report was developed in accordance with the protocols identified in Task Technical and Quality Assurance Plan SRNL-RP-2013-00310 by Reboul and others [2013]. 
SRNL-STI-2013-00544

Revision 0

\subsection{SRS Sampling}

Most DWPF sampling studies were based on in-tank sampling or on downstream sampling after transfers. The latter includes samples from other vessels as well as samples from the final glass product. Other studies were based on full-sized tanks at SRNL's former Technical Annex (TNX), scaled-down tanks that were designed to model key characteristics of process vessels, or laboratory-scale studies of glass properties.

Tanks with capacities similar to those within the DWPF, say with capacities on the order of 10,000 gallons or less, generally have advantages of accessibility for sampling. These situations offer the best opportunities to study potential spatial differences in chemical or physical properties of tank material due to incomplete mixing or settling, or due to sampling issues associated with the location or operational characteristics of the sampling device. It will be seen in Section 4.1 that one basic sampling model that takes advantage of tank accessibility is prototypic of many of the sampling studies for the DWPF whose objectives were to investigate homogeneity of the tank material or to determine whether the samples obtained from the installed sampling device met specified standards of representativeness for the material within the tank.

Large storage tanks, on the order of one million gallons capacity, have fewer points of access from which to draw samples. Churnetski [1981] reported testing of half-tank and full tank mockups at SRNL to determine the zone of influence, i.e., the effective cleaning radius, of slurry pumps as a function of pump operating parameters (pump nozzle diameter and pump nozzle velocity) and waste properties (slurry yield stress and slurry density). In addition, the SRS Tank Farm conducted tests in actual waste tanks to determine the zone of influence of the pumps. As reported by Poirier [1995], SRS Tank Farm personnel used the results of these tests to determine the pump operating parameters (pump nozzle diameter and pump nozzle velocity) to ensure the tanks were well mixed for sludge removal and tank sampling. Typically these tanks, with highly radioactive material and sometimes internally laced with cooling coils and containing valve housings and other obstructions, have restricted access by way of riser locations from the top of the tank. Potential sampling plans for studying spatial differences in the storage tanks in the SRS Tank Farms are limited by these physical barriers, while the size and internal obstructions create greater challenges to mix and adequately sample the tank contents. However, these challenges were mitigated by relatively wider requirements needed for the accuracy and precision of samples and measurements for the large storage tanks in the SRS Tank Farm (SRS [2010]) that feed the DWPF process than were required for the smaller tanks such as the SME within the DWPF itself. These differences in requirements are due to inherently different goals for the Tank Farm and DWPF data: the Tank Farm data are used to assure safe storage, while the DWPF data are used to assure effective glass production. While both applications require quality data, the range of acceptable conditions for safe storage is significantly wider than that required for effective glass production.

In two decades of the DWPF operation, no batch of material has been transferred from the Tank Farm to the SME that required rework in order to be processed or led to the DWPF glass product that simply failed to comply with the acceptability constraints. Thus, the current capability to characterize the 
chemical composition and physical properties of tank material in the SME or in the Tank Farm prior to its transfer to the DWPF meets the challenges of producing acceptable glass product.

Some of the DWPF studies, such as Edwards ${ }^{1}$ [2008], studied mixing procedures for large capacity storage tanks in the SRS Tank Farm by taking advantage of sampling from downstream tanks after transfers, since the objective was to determine how mixing in the large tank affected downstream characteristics of the tank material.

This report describes some of the key DWPF sampling studies at SRS. The perspective is one of methodology rather than results. For example, one of the examples cited in this report demonstrated that the tank contents were not homogeneous with regard to certain material characteristics. Thus, not every study resulted in validation of the process. Some studies became challenges to learn from the data and improve the process, the mixing, and the sampling. Lessons learned during the startup and operation of the DWPF were discussed by Cercy and Others [2013]. Many of the early startup sampling activities took place in the 1992 to 1995 time period. This period was before the time of electronic report filing, and many contributors to these early studies have since retired. Thus the bulk of this report was based on paper copies of documents.

Multiple methods of assessing sampling and analysis uncertainties, tailored to specific site applications, are utilized at SRS. Although this report targets those associated with DWPF, it should be noted that alternate methods of assessing uncertainties in other site projects include those reported by Harris [2010a and 2010b], Oji and Others [2013], Shine [2010 and 2013], and Analytical Laboratories [2007a and 2007b].

\footnotetext{
${ }^{1}$ The study by Edwards [2008] is reviewed in Section 4.4.
} 
SRNL-STI-2013-00544

Revision 0

\subsection{Sampling and the Pierre Gy Sampling Technology}

The statistics literature has been replete with sampling studies for more than a century. Unfortunately, the bulk of these studies are associated with surveys of people, or quality control and product acceptance sampling, not of material that requires sampling that may be sensitive to the physical properties and chemical composition of the material itself. Many other sampling studies are associated with environmental sampling. Environmental samples have both physical dimensions and in many instances their focus is an understanding of chemical properties. Still the early development of environmental sampling paralleled the developments of surveys, ignoring the fundamental nature of the material to be sampled. Addressing this oversight, a formal theory of particulate sampling was introduced by Pierre Gy and described in his book [1979]. Several books have since been published to provide access to these ideas to a broader audience. At SRNL, the first author was exposed to some of these ideas in the early 1990s through a two-volume compendium from Pitard [1989], but only a small portion of that author's work included environmental studies including geostatistics, and included almost no applications to industrial, non-reactor processes.

Tank "homogeneity" is used repeatedly in this report because it was the title or the stated objective of many studies. This usage may be contrary to the ideas in the Gy sampling literature, as homogeneity is viewed as a limiting case, not a reality for material such as that in SRS tanks. Nonetheless, goals for precision and accuracy were explicitly expressed in many reports, and sampling tests were designed to demonstrate whether the system could achieve these goals. These studies assessed the suitability of mixing and sampling processes, though the effects studied were not placed in now well-known categories for sampling errors.

The history of SRS sampling studies shows that technical tasks were split between a cognizant engineering function and statistical specialists that were members of the investigative teams. The fundamental selection of mixing equipment, sampling devices, and their operational parameters were in the providence of the engineers. For example, Poirier [2004] provided recommendations for mixing problems in the SRS Tank Farm. Understanding the characteristics of these tools, the properties of the tank material, and the objectives of the mixing task also aided the engineers to design the fundamental structure of the tank tests that could demonstrate tank homogeneity and representative sampling if the tests turned out to be successful. The fundamental requirements for testing were specified in engineering reports such as Jenkins [1992]. No documents were obtained by the author that could indicate that the engineers followed or were influenced by the system of sampling formulated by Pierre Gy, so it may be concluded that the Gy sampling system was not well known and therefore not used in the early years at the DWPF. However, the SRS teams understood the concept of sample representativeness as described by Pitard [1989], established quantitative standards for sample representativeness, and executed sampling strategies to acquire data to demonstrate whether the representative standard was met. The Gy approach leads to a systematic evaluation of the engineered devices and processes relative to the goal of sample representativeness, but the DWPF processes, having been demonstrated to meet the established criteria of sample representativeness, achieved their stated goals using possibly alternative approaches. Whether the 
Gy sampling approach would have led to greater "optimization” of system parameters or a shorter learning curve cannot be known.

Once engineers established the testing framework, the statistical specialists determined the number of samples of various types and the number of measurements per sample that needed to be obtained in order to meet goals for precision and accuracy in as practical and economic a manner as possible. The statisticians documented formal statistical tests that could determine whether the goals for representative samples were met, and quantified many of the components of measurement uncertainty for the DWPF tanks. Once the samples were obtained and sent to the laboratory, the statisticians partitioned the samples into separate preparation blocks that could be analyzed independently. The samples were randomized to the greatest extent possible.

Studies of the mixing and sampling capabilities supported qualification of the DWPF process. The following sections of this report describe case studies of mixing/sampling studies that typify the approaches used at SRS to support qualification of the DWPF process. 
SRNL-STI-2013-00544

Revision 0

\subsection{Case Studies}

Many sampling studies have been performed in the development and qualification of the DWPF process. Several of these studies have been selected and reported here since they were highly successful approaches to study variability of feed streams and glass product at SRS. Generally a sampling design could address multiple objectives. These case studies have been organized by general aims of the study. Section 4.1 presents details of tank homogeneity and liquid sampler testing at DWPF. These designed studies were based on various comparisons with samples obtained directly from tanks, many of which were mock ups. Section 4.2 covers macrobatch uniformity studies at SRS. Unlike the designed studies in Section 4.1, these investigations were based on sampling information collected during DWPF processing. Section 4.3 discusses studies of the chemical composition and uniformity of the waste glass itself. Section 4.4 introduces studies of the pumping, mixing, and transfer technologies. Each of these topics is associated with sample representativeness: the capability to mix well and to evaluate the effectiveness of the mixing of the DWPF tanks, the settings for mixing equipment, the selection of samplers that produce samples that are representative of the tank contents, and a description of tank homogeneity from welllocated and sufficient numbers of samples from a tank. 


\subsection{Tank Homogeneity and Liquid Sampler Testing}

The suitability of the installed liquid sampler is an important concern in supporting reliable and accurate process measurements that ensure the DWPF produces melter feed that is within an acceptable compositional range without rework. Failure to achieve representative samples of the DWPF liquid slurry feed stream could yield melter feed material that is out-of-specification leading to the need to either adjust the mixture in the SME or failure of the glass to meet product specifications. Ray and others [2012b] state that if a SME batch is acceptable, it is forwarded to the MFT; if it is found to be unacceptable it will be held in the SME and remediated until it is acceptable. Since waste glass can neither be remediated nor reworked, the melter feed material must be found acceptable (while it is in the SME) before it is melted. Representative sampling is important throughout the DWPF process, and the demonstrated success of the DWPF process to achieve glass product quality over the past two decades is a direct result of the quality of information obtained from the process.

The particular sampling design discussed in this section has been a much applied method beginning with early development and startup studies. Edwards [1992a] used this design to study the homogeneity of the MFT under static and dynamic conditions with high weight percent (wt \%) solids and again with low wt \% solids, and Edwards [1992c] studied the performance of the Hydragard ${ }^{\mathrm{TM}}$ sampler in the Precipitate Reactor Bottom Tank (PRBT). Later the design was modified by Edwards [1994a] to study the MFT under static and dynamic conditions but using only one placement of the grab sampler at a high and a low level that was compared with the Hydragard ${ }^{\mathrm{TM}}$ sampler and again by Edwards [1994b] using only high and low grab samples to study potential issues of settling in the MFT. These studies have continued, extending to recently completed investigations, Edwards [2009] and [2010]. This series of experiments also demonstrate that one test can serve multiple purposes. Testing of installed sampling devices demands some comparison with a more fundamental sample or set of samples that can be considered to represent the tank contents. When the situation permits sampling in a number of radial locations and depths, the resultant set of samples can be a useful comparison with samples obtained from an installed device, especially if the in-tank samples did not rely on the same physical mechanisms of acquiring the sample material as the installed sampler. The acquisition of a set of samples systematically gathered from various tank locations also provides an opportunity to compare results across different regions of the tank, leading to a study of the homogeneity of the tank contents. The data from such a study also provide an opportunity to evaluate measurement uncertainties and determine the relative impact of sampling, sample preparation, and measurement operations on the uncertainty of the reported results.

Edwards [2010] documented the statistical design, and Hera and others [2011] assessed the results from a recent study of the viability of the Isolok ${ }^{\mathrm{TM}}$ sampler. The plan was executed in a 1/6-scale SME tank with an agitator and recirculation system that allowed samples to be taken with either the Hydragard ${ }^{\mathrm{TM}}$ sampler or the Isolok ${ }^{\mathrm{TM}}$ sampler. A Hydragard ${ }^{\mathrm{TM}}$ sampler operates by a continuous flow through the sampling vial while an Isolok ${ }^{\mathrm{TM}}$ sampler extracts a grab sample from the process line. The study used a slurry of sludge simulant and frit that is described in the Edwards [2010] report. 
The test objectives were to investigate the performance of the Isolok ${ }^{\mathrm{TM}}$ sampler which was being considered as a replacement for the Hydragard ${ }^{\mathrm{TM}}$ sampler and to investigate vertical differences between high and low grab samples. The Isolok ${ }^{\mathrm{TM}}$ and Hydragard ${ }^{\mathrm{TM}}$ samples were compared to an average of high and low grab samples obtained directly from the SME using a composite liquid waste sampler (Coliwasa). The sampling configuration for the Coliwasa samples is depicted in Figure 1. Pairs of high and low Coliwasa samples at the same radial locations are connected by vertical white lines, and all Coliwasa samples at the same vertical height are connected by dashed black rings in the figure.

Noting that the high and low Coliwasa samples formed a paired comparison design, Edwards [2010] based the test of the difference between the means of measurements between the high and low Coliwasa samples on the Student's t distribution. The two-sided test is based on the following design criteria.

1. The level of significance, $\alpha$ : the probability of falsely rejecting the null hypothesis of no difference between the two means.

2. The magnitude of a difference between the means to be detected, $\Delta$, and a probability, $1-\beta$, that a difference of at least magnitude $\Delta$ will be detected.

3. An estimate of the standard deviation for the difference between two measurements, $\sigma_{\text {diff }}$, in the same units of measure as $\Delta$.

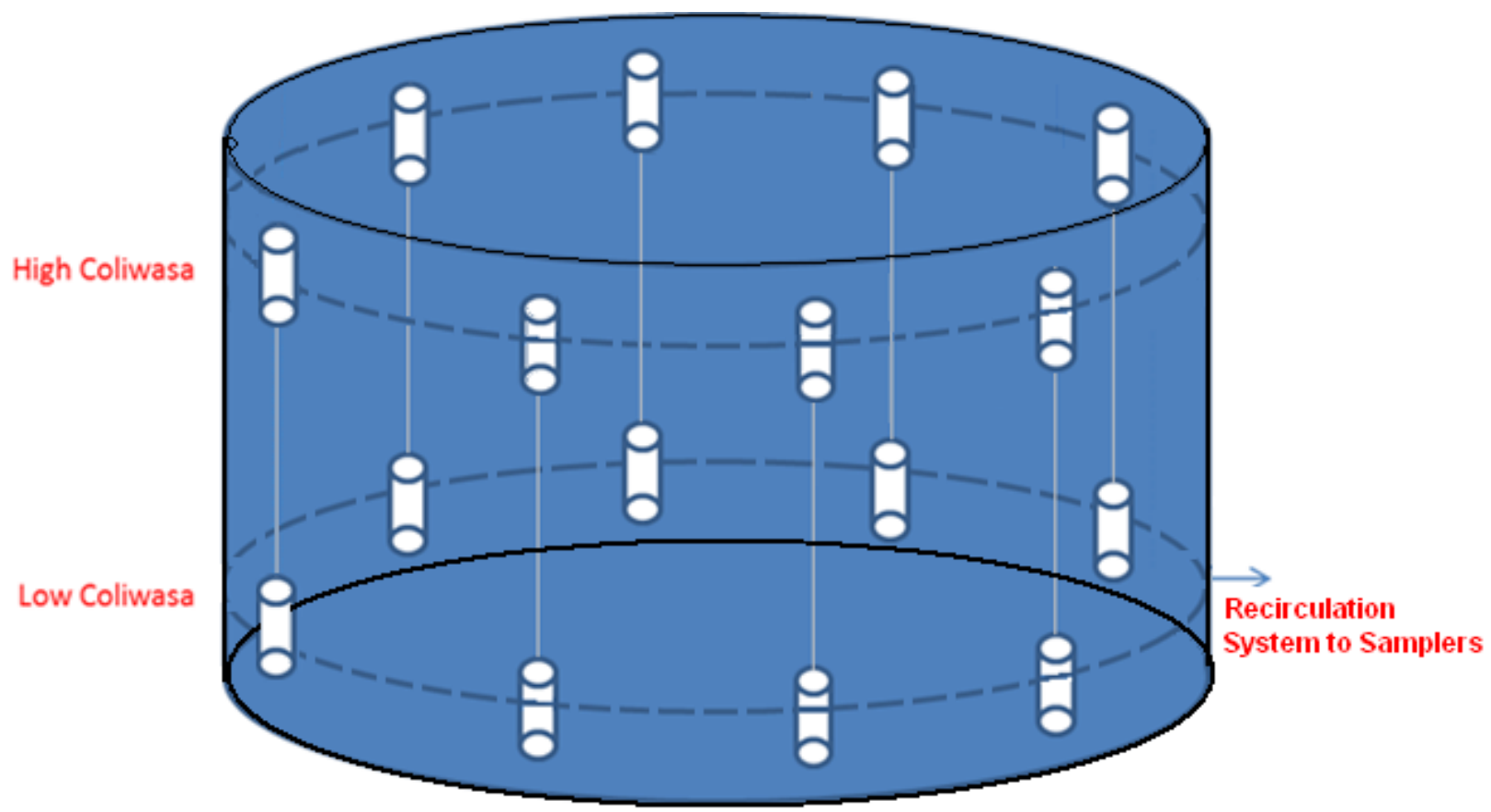

Figure 1. Arrangement of Coliwasa Grab Samples in the SME 
The number of (radial positions) pairs of Coliwasa samples is determined by Formula (1).

$$
n_{\text {pairs }}=\frac{\sigma_{\text {diff }}^{2}\left(t_{1-\alpha / 2, d f}+t_{1-\beta, d f}\right)^{2}}{\Delta^{2}} \text { (fractional values are rounded up to the next whole number), }
$$

where $t_{1-\alpha / 2, d f}$ and $t_{1-\beta, d f}$ are the (1-(a/2))-th and (1- $\left.\beta\right)$-th quantiles of the Student's t distribution with $d f=n_{\text {pairs }-1}$ degrees of freedom, respectively. Formula (1) is generally solved iteratively since the result, $n_{\text {pairs }}$, on the left side of the formula determines the number of degrees of freedom for the Student's $t$ quantile on the right side of the formula.

Assuming a relative sampling standard error for the difference between two measurements, $\sigma_{\text {diff }}=4 \%$, Edwards [2010] determined that eight pairs of high and low Coliwasa samples were minimally sufficient to observe a vertical sample bias of $5 \%$ or more with at least $80 \%$ probability. Using a trial number of 7 pairs of samples and then a trial number of 8 pairs of samples in Formula (1), Edwards obtained the following results.

$$
n_{\text {pairs }}=\left\{\begin{array}{r}
\frac{(4 \%)^{2}(2.447+0.906)^{2}}{(5 \%)^{2}}=7.19 \text { rounds up to 8, if } 7 \text { pairs of samples yielding } d f=7-1=6 \\
\quad \text { was used for the Student t quantiles in Formula (1), and } \\
\frac{(4 \%)^{2}(2.365+0.896)^{2}}{(5 \%)^{2}}=6.81 \text { rounds up to } 7, \text { if } 8 \text { pairs of samples yielding } d f=8-1=7 \\
\text { was used for the Student t quantiles in Formula (1). }
\end{array}\right.
$$

The trial number of 7 pairs of samples yielded $n_{\text {pairs }}=8$ samples as the required minimum. This demonstrates that 7 pairs of samples were too few. The trial number of 8 pairs of samples yielded $n_{\text {pairs }}=$ 7 samples as the required minimum. Since 7 pairs of samples were demonstrated to be inadequate in the first calculation of Formula (2), and the trial number of 8 pairs of samples exceeded the derived minimum of 7 pairs of samples in the second calculation of Formula (2), then 8 is the minimum number of pairs of samples needed to meet the sampling criteria.

The differences $X_{\text {diff }(i)}=x_{\text {High }(i)}-x_{\text {Low }(i)}$ between the measurements from the high and the low Coliwasa samples at particular radial positions $i=1,2, \ldots, n_{\text {pairs }}$ were computed. The mean and the standard deviation of the $n_{\text {pairs }}$ differences are $\bar{x}_{\text {diff }}=\sum_{i=1}^{n_{\text {pairs }}} x_{\text {diff }(i)} / n_{\text {pairs }}$ and $s_{\text {diff }}=\sqrt{\sum_{i=1}^{n_{\text {pairs }}}\left(x_{\text {diff }(i)}-\bar{x}_{\text {diff }}\right)^{2} /\left(n_{\text {pairs }}-1\right)}$, respectively. 
Formula (3) is used to compute a confidence interval for the true (unknown) difference between the means of the measurements on the high and the low Coliwasa samples. If the value zero is not contained within the confidence interval in Formula (3), then the test rejects the null hypothesis of no true mean difference between measurements from samples obtained by the Coliwasa in the high and low regions of the tank.

$$
\bar{x}_{\text {diff }} \pm t_{1-(\alpha / 2), d f} \frac{s_{\text {diff }}}{\sqrt{n_{\text {pairs }}}} .
$$

A test between the overall mean of the measurements on the Coliwasa samples and the mean of the measurements from each installed sampler was also required. The Coliwasa samples were considered independent of the samples from the installed samplers. The numbers of Coliwasa samples and samples from each installed sampler were initially assumed to be equal. Edwards [2010] also based this test on the Student's t distribution. The two-sided test uses the following design criteria.

1. The level of significance, $\alpha$ : the probability of falsely rejecting the null hypothesis of no difference between the two means.

2. The magnitude of a difference between the means to be detected, $\Delta$, and a probability, 1- $\beta$, that a difference of at least magnitude $\Delta$ will be detected.

3. An estimate of the standard deviation for both types of sampling (assumed to be the same), $\sigma$, in the same units of measure as $\Delta$.

The sample sizes for the number of Coliwasa samples and for the number of samples from an installed sampler are both given by Formula (4).

$$
n=\frac{2 \cdot \sigma^{2}\left(t_{1-(\alpha / 2), \text { df }}+t_{1-\beta, d f}\right)^{2}}{\Delta^{2}} \quad \text { (fractional values are rounded up to the next whole number), }
$$

where $t_{1-(\alpha / 2), \text { df }}$ and $t_{1-\beta, d f}$ are the (1-(a/2))-th and (1- $\left.\beta\right)$-th quantiles of the Student's t distribution with $d f=2(n-1)$ degrees of freedom, respectively. Formula (4) is generally solved iteratively since the result, $n$, on the left side of the formula determines the number of degrees of freedom for the Student's t quantile on the right side of the formula. Each sampling method is required to have at least $n$ samples to satisfy the design criteria.

Assuming a relative sampling standard deviation, $\sigma=4 \%$, Edwards [2010] determined that 12 Coliwasa samples and 12 samples from each of the installed samplers were minimally sufficient to observe a relative sampling bias of $5 \%$ or more with at least $80 \%$ probability. Using a trial number of 11 samples of per sample type (2 types: Coliwasa and an installed sampler), and then a trial number of 12 samples of per sample type in Formula (4), Edwards obtained the following results. 


$$
n=\left\{\begin{aligned}
& \frac{2 \cdot(4 \%)^{2}(2.074+0.858)^{2}}{(5 \%)^{2}}= 11.004 \text { rounds up to } 12, \text { if } 11 \text { samples per sample type yielding } \\
& d f=2 \cdot(11-1)=20 \text { was used for the Student t quantiles in } \text { Formula (4), and } \\
& \frac{2 \cdot(4 \%)^{2}(2.064+0.857)^{2}}{(5 \%)^{2}}= 10.921 \text { rounds up to } 11 \text {, if } 12 \text { samples per sample type yielding } \\
& d f=2 \cdot(12-1)=22 \text { was used for the Student } t \text { quantiles in } \\
& \text { Formula (4). }
\end{aligned}\right.
$$

The trial number of 11 samples per sample type yielded $n=12$ samples per sample type as the required minimum. This demonstrates that 11 samples per sample type were too few. The trial number of 12 samples per sample type yielded $n_{\text {pairs }}=11$ samples per sample type as the required minimum. Since 11 samples per sample type were demonstrated to be inadequate in the first calculation of Formula (5), and the trial number of 12 samples per sample type exceeded the derived minimum of 11 samples per sample type in the second calculation of Formula (5), then 12 is the minimum number of samples per sample type needed to meet the sampling criteria if both sample types are to have the same number of samples. However, since 12 samples are less than the number previously determined for the Coliwasa samples, 16, the number of samples from the installed samplers could be lowered and still satisfy the design criteria.

Formula (6) is the sample size formula for the number of samples, $n_{\text {sampler, }}$, from each of the installed samplers in order to perform a two-sided test of the difference of the means of the measurements from two independent samples when the Coliwasa and installed sampler samples sizes are permitted to differ. The number of Coliwasa sample pairs was determined in Formula (2), and the total number of Coliwasa samples (two times the number of Coliwasa pairs of samples) is denoted by $n_{\mathrm{C}}$. The number of samples determined for this test from the equal sample size calculation in Formula (5) is denoted by $n$. Then

$$
n_{\text {sampler }}=\frac{n \cdot n_{C}}{\left(2 \cdot n_{C}\right)-n} \quad \text { (rounded up to the next whole number). }
$$

Since the number of Coliwasa samples was previously determined to be $n_{\mathrm{C}}=2 \cdot 8=16$, and the calculated sample sizes for the comparison of the Coliwasa and each of the installed samplers were $n=12$ (assuming equal sample sizes) from Formula (5), the number of samples required for the installed samplers is 10 each. Using Formula (6),

$$
n_{\text {sampler }}=\frac{12 \cdot 16}{(2 \cdot 16)-12}=9.6 \text { which rounds up to } 10 \text { samples for each sampler. }
$$

A confidence interval for the true (unknown) difference between the means of the measurements on the samples from the installed sampler and the Coliwasa is given in Formula (8). 


$$
\left(\bar{x}_{\text {sampler }}-\bar{x}_{C}\right) \pm t_{1-(\alpha / 2), d f} \cdot S_{\text {pooled }} \sqrt{\frac{1}{n_{\text {sampler }}}+\frac{1}{n_{C}}},
$$

where the means of the measurements from the samples obtained from the installed sampler and from the Coliwasa were $\bar{x}_{\text {sampler }}$ and $\bar{x}_{C}$, respectively. The pooled standard deviation was $s_{\text {pooled }}=\sqrt{\left[\left(n_{\text {sampler }}-1\right) s_{\text {sampler }}^{2}+\left(n_{C}-1\right) s_{C}^{2}\right] /\left[n_{\text {sampler }}+n_{C}-2\right]}$, where the standard deviations of the measurements from the samples obtained from the installed sampler and from the Coliwasa were $s_{\text {sampler }}$ and $s_{C}$, respectively, and $t_{1-(\alpha / 2), \text { df }}$ is the (1-(a/2))-th quantile of Student's t distribution with $d f=n_{\text {sampler }}+n_{C}-2$ degrees of freedom.

If the value zero is not contained within the confidence interval in Formula (8), then the test rejects the null hypothesis of no true mean difference between measurements from samples obtained from the installed sampler and the Coliwasa.

The measurements to be performed were wt \% dried solids, wt \% vitrified solids, and elemental compositions of the vitrified samples. The preparations and analyses were partitioned into separate blocks that could be performed independently. Random orders for samples within preparation blocks and random orders for prepared samples within analysis blocks were provided. Standard samples were analyzed along with the tank samples for quality control purposes.

The tests were successful in demonstrating that the Isolok ${ }^{\mathrm{TM}}$ sampler is a viable option for taking SME samples.

An earlier study reported by Edwards [1992c] provided evidence that the test design was sufficiently sensitive to detect spatial effects if present. This was the result of establishing standards for detecting differences and determining the minimally sufficient number of samples to meet the stated standards at the experimental design stage. Similar to the previous example, Jenkins' [1992] task plan reported that the major objectives of this test were to investigate in-tank homogeneity and evaluate the Hydragard ${ }^{\mathrm{TM}}$ sampler performance.

In this test, the Precipitator Reactor Bottom Tank (PRBT) had been filled to a liquid level of 103 inches, and high grab samples were taken about 6 to 12 inches below the surface. Low grab samples were obtained about 20 inches off the bottom of the tank: about the same height as the Hydragard ${ }^{\mathrm{TM}}$ sampler. Six major elemental components, Ti, B, Na, K, Na-AA ${ }^{2}$, K-AA, and three minor elemental components, $\mathrm{Cu}, \mathrm{Fe}$, and $\mathrm{Mn}$, were measured. Tank samples from this test had showed that $\mathrm{Ti}, \mathrm{Fe}$, and Cu were the most insoluble constituents. A comparison of the high and low grab sample measurement results indicated that the more soluble metals were consistent with regard to in-tank vertical homogeneity, and that

\footnotetext{
${ }^{2}$ The elemental measurements were performed by Inductively Coupled Plasma-Atomic Emission (ICP), except where noted by AA which denotes the measurements were done by Atomic Absorption.
} 
comparisons of measurements on samples from both sets of grab samples to the Hydragard ${ }^{\mathrm{TM}}$ sampler indicated those metals were not sensitive to the Hydragard ${ }^{\mathrm{TM}}$ sampler. However, statistically significant differences between the high and low grab samples demonstrated that the tank was not homogeneous with respect to the insoluble metals, and despite the low grab samples being at the same height as the

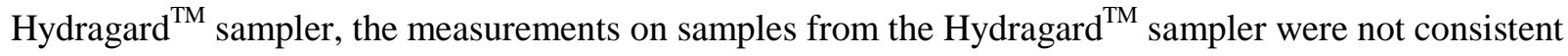
with the low grab samples for the insoluble metals. This test demonstrated that not all the DWPF testing results led to immediate validation of the DWPF processes in the early years of development. Studies such as this one were used as platforms for additional engineering work that led to later sampling improvements.

Pierre Gy has defined delimitation and extraction errors. Every part of the sample must have an equal probability of being selected in order to delineate a correct sample. Otherwise, a delineation error occurs. An extraction error occurs if the correct delineation cannot be obtained. Sampling studies at SRS have demonstrated that the Hydragard ${ }^{\mathrm{TM}}$ sampler and the Isolok ${ }^{\mathrm{TM}}$ sampler exhibit extraction errors. In a series of experiments, sampling devices such as the Hydragard ${ }^{\mathrm{TM}}$ sampler and the Isolok ${ }^{\mathrm{TM}}$ sampler have been compared to samples drawn directly from a tank in order to study sampler properties. Obtaining Coliwasa samples directly from a mixed tank can approximate a correct sample, at least for the region from which the sample was taken. By systematically sampling the vertical extremes of the tank contents and obtaining samples at a number of radial locations, a statistical assessment can be performed to determine whether the tank contents have been adequately mixed. If a comparison leads to the conclusion that the samples taken at the vertical extremes are consistent within the limits of measurement error, then the overall average of the grab samples can be considered to be representative of the tank contents. Since the Coliwasa samples did not depend on the same sampling technologies underlying the Hydragard ${ }^{\mathrm{TM}}$ or Isolok $^{\mathrm{TM}}$ samplers, an evaluation of their extraction errors could be made for the Hydragard ${ }^{\mathrm{TM}}$ and Isolok $^{\mathrm{TM}}$ samplers if needed. 


\subsection{Macrobatch Uniformity}

A macrobatch was defined in the Introduction as containing salt feed, sludge, and frit. It contains a portion of sludge during periods of relatively constant glass composition. Edwards [2003] has studied the chemical and radionuclide compositions ${ }^{3}$ of macrobatches ${ }^{4} \mathrm{MB} 1 \mathrm{a}$ and MB1b using Hydragard ${ }^{\mathrm{TM}}$ samples from each process batch. MB1a and MB1b are two different macrobatches, and the reason for the change in identification number is that they are from different sludge tanks comprising the feed. The analyses had the following primary objectives.

- Determine the uncertainty associated with the direct and the indirect methods for reporting the radionuclide inventory for a DWPF macrobatch.

- Compare samples from the SME and the MFT to determine if sufficient variation exists to justify continued sampling of the MFT for each process batch.

- Compare the two methods of sample preparation.

This study had multiple objectives. The primary focus of the report was the comparison of the SME and MFT samples. Inferences regarding the mixing of Tank $40 \mathrm{H}$ were not a stated objective of this report, but ancillary results were produced that can be reported here. For example, batch-to-batch and within batch variation were assessed as a preliminary step to determine the uncertainty for reporting a radionuclide inventory for a macrobatch. These sources of variation, especially for SRAT receipt sampling, provide insight into the extent to which Tank $40 \mathrm{H}$ was mixed and Tank 51 was mixed.

The analysis related to the second objective examined average percent differences between chemical measurements from paired samples from SME and MFT batches. While the analysis concluded that the MFT samples were largely redundant, the analysis was based on a paired comparison design which controlled for batch-to-batch variation, that is, the analysis treated batch-to-batch variation as a nuisance effect, not as a factor to be studied. Consequently, those results are not discussed in this report because they do not provide any insight into the variability between process batches. The third objective pertains to a comparison of results for two preparation methods. The analysis supporting the comparison is not related to sampling, so those results also are not discussed in this report.

The study of the batch-to-batch and within batch (residual) variations was based on a simple random effects model in Formula (9).

\footnotetext{
${ }^{3}$ This report included analyses for radionuclides for macrobatches MB1 and MB2 (renamed MB1a and MB1b, respectively). The chemical composition for MB1 (now MB1a) was analyzed in an earlier report by Edwards [2000] so only the chemical analyses for MB2 (now MB1b) were studied in this report.

${ }^{4}$ The Edwards report refers to macrobatches MB1 and MB2: subsequent to its publication, the macrobatches MB1 and MB2 were renamed MB1a and MB1b, respectively. The latter macrobatch identifiers will be used in this report. Sludge Batch SB1 was split into MB1a and MB1b. Transition to MB1b was at SRAT Receipt Batch 94, and transition to MB2 was at SRAT Receipt Batch 208.
} 


$$
\text { Result }_{j(i)}=\text { Overall Average }+ \text { Process Batch Effect }_{i}+\text { Residual Effect }_{j(i)} \text {, }
$$

where there were six samples obtained from each process batch. A particular process batch was labeled $i$, and a particular sample $j$ from process batch $i$ was labeled $j(i)$, read "sample $j$ with batch $i$ ". Result ${ }_{j(i)}$ is the measured concentration of some analyte on sample $j(i)$. The actual average concentration for all batches is Overall Average, and the Residual Effect ${ }_{j(i)}$ is the accumulation of sample-to-sample and analytical/measurement errors for sample $j$ obtained from process batch $i$. Two variances are defined: the batch-to-batch variance $\sigma_{b}^{2}$ and the residual variance $\sigma^{2}$. The random effects model in Formula (9) was fit separately to results from the measured concentrations of analytes from samples obtained from the SRAT Receipt, the SRAT Product, the SME, and the MFT from MB1b.

Edwards [2003] reports, "For most of the analytes for each of the four vessels, the batch-to-batch variation is larger than the residual variation". The uniformity of process batches from MB2 (now named MB1b) at each vessel is provided for each analyte by the percent coefficient of variation for this batch-tobatch variability for the analyte, which expresses the variation in the measurements for this analyte as the standard deviation divided by the average.” An abbreviated table of Edwards' [2003] results for the SRAT receipts from MB1b is provided in Appendix A Table A1. The coefficients of variation, also referred to as relative standard deviations in percent units and denoted by \%RSD, are given in Appendix A Table A1 for batch-to-batch variation, residual (within batch) variation, and their root-sumsquare, labeled as \%RSD Total. The batch-to-batch and residual variances (squares of their \%RSDs) have been normalized so the total variance equals $100 \%$, and are listed under "Components of Variation". The batch-to-batch component of variance is seen to dominate the residual component of variance for all chemical concentrations except sulfate and sodium.

Tables 1 and 2 on Page 18, reproduced from Edwards [2003], summarize the radionuclide components of variance for MB1a and MB1b, respectively. Only samples from the MFT were provided in that report. As shown in the tables, the mean concentrations of key radionuclides in MB2a were higher than those in MB1a. Specifically, the concentrations of Cs-137, Sr-90, and Pu-238 in MB2a were higher than those in MB1a by factors of $~ 2.5, ~ 7.6, ~ 1.2$, respectively.

The batch-to-batch component of variance in Tables 1 and 2 was larger than the residual component of variance for Cs-137, Sr-90, and Pu-238 in MB1a and in MB1b. The normalized components of variance, denoted by “\% Variance Components" are also provided in Tables 1 and 2. For MB1a, the batch-to-batch variance was about $60 \%$ of the total variance for all three radionuclides. For MB1b, the batch-to-batch variance for Cs-137 was also about $60 \%$ of the total variance. The batch-to-batch variance for Sr-90 was about $75 \%$ and the batch-to-batch variance for Pu-238 was about $88 \%$ in MB1b. 
SRNL-STI-2013-00544

Revision 0

Table 1. Components of Variance for the Radionuclide Concentrations from MB1a

\begin{tabular}{|c|c|c|c|c|}
\hline & Analyte & Cs-137 (Bq/g) & Sr-90 (Bq/g) & Pu-238 (Bq/g) \\
\hline & Mean & 879256.1 & 6877185 & 760126.2 \\
\hline & \% Std. Error of Mean & $0.8 \%$ & $1.5 \%$ & $1.2 \%$ \\
\hline \multirow{2}{*}{$\begin{array}{l}\% \text { Variance } \\
\text { Components }\end{array}$} & \begin{tabular}{|l|} 
Batch \\
\end{tabular} & $58.7 \%$ & $62.7 \%$ & $60.0 \%$ \\
\hline & Residual & $41.3 \%$ & $37.3 \%$ & $40.0 \%$ \\
\hline \multirow{3}{*}{$\begin{array}{c}\text { Components } \\
\text { of } \\
\text { Variance }\end{array}$} & Total & $5.424 \mathrm{E}+09$ & $9.800 \mathrm{E}+11$ & $8.052 \mathrm{E}+09$ \\
\hline & Batch & $3.184 \mathrm{E}+09$ & $6.146 \mathrm{E}+11$ & $4.829 \mathrm{E}+09$ \\
\hline & Residual & $2.240 \mathrm{E}+09$ & $3.654 \mathrm{E}+11$ & $3.223 \mathrm{E}+09$ \\
\hline \multirow{6}{*}{$\begin{array}{c}\% \% \\
\text { Relative } \\
\text { Std Deviation }\end{array}$} & \%RSD Total & $8.4 \%$ & $14.4 \%$ & $11.8 \%$ \\
\hline & \%RSD Batch & $6.4 \%$ & $11.4 \%$ & $9.1 \%$ \\
\hline & \%RSD Residual & $5.4 \%$ & $8.8 \%$ & $7.5 \%$ \\
\hline & Mean Squares & $1.890 \mathrm{E}+10$ & $2.810 \mathrm{E}+12$ & $2.510 \mathrm{E}+10$ \\
\hline & Degrees of Freedom & 69 & 67 & 69 \\
\hline & $\mathbf{N}$ & 367 & 270 & 317 \\
\hline
\end{tabular}

Table 2. Components of Variance for the Radionuclide Concentrations from MB1b

(Edwards, WSRC-TR-2003-00045, Table 12)

\begin{tabular}{|c|c|r|r|r||}
\hline & Analyte & Cs-137 (Bq/g) & Sr-90 (Bq/g) & Pu-238 (Bq/g) \\
\hline \hline & Mean & 2159126 & 52040625 & 916302 \\
\cline { 2 - 5 } & \% Std. Error of Mean & $0.7 \%$ & $0.9 \%$ & $1.7 \%$ \\
\hline \multirow{3}{*}{$\begin{array}{c}\text { \% Variance } \\
\text { Components }\end{array}$} & Batch & $56.4 \%$ & $74.7 \%$ & $88.2 \%$ \\
\cline { 2 - 5 } $\begin{array}{c}\text { Components } \\
\text { of } \\
\text { Variance }\end{array}$ & Residual & $43.6 \%$ & $25.3 \%$ & $11.8 \%$ \\
\cline { 2 - 5 } & Total & $4.197 \mathrm{E}+10$ & $3.289 \mathrm{E}+13$ & $3.165 \mathrm{E}+10$ \\
\cline { 2 - 5 } $\begin{array}{c}\text { \%elative } \\
\text { Std Deviation }\end{array}$ & Batch & $2.37 \mathrm{E}+10$ & $2.46 \mathrm{E}+13$ & $2.79 \mathrm{E}+10$ \\
\cline { 2 - 5 } & Residual & $1.83 \mathrm{E}+10$ & $8.31 \mathrm{E}+12$ & $3.74 \mathrm{E}+09$ \\
\cline { 2 - 5 } & \%RSD Total & $9.5 \%$ & $11.0 \%$ & $19.4 \%$ \\
\cline { 2 - 5 } & \%RSD Residual & $7.1 \%$ & $9.5 \%$ & $18.2 \%$ \\
\cline { 2 - 5 } & Degrees of Freedom & $6.3 \%$ & $5.5 \%$ & $6.7 \%$ \\
\cline { 2 - 5 } & $\mathbf{N}$ & 111 & $1.07 \mathrm{E}+14$ & $1.50 \mathrm{E}+11$ \\
\hline \multirow{2}{*}{ \%R+11 } & 629 & 448 & 111 \\
\hline
\end{tabular}

Edwards [2003] provided plots of the measured characteristics for samples from the SRAT receipt, the SRAT product, the SME, and the MFT. The SRAT receipt and product samples represent SRAT process batches before and after treatment to neutralize the alkaline waste and reduce mercury. Of these samples, the SRAT receipt samples are the first set of samples taken after transfers to the SRAT from Tanks $40 \mathrm{H}$ and 51H. Appendix A Exhibit A1 reproduces several of the plots of measured characteristics from the SRAT Receipt samples from MB1b. The plots are by the SRAT batch number so that batch-to-batch uniformity could be assessed by the report investigators. Plot (a) of the Total Solids Concentrations (wt \%) and Plot (b) of the Calcined Solids Concentrations (wt \%) show a slight decrease from Batch 110 to Batch 200. This suggests a high solids concentration near the bottom of the vessel, bearing water leakage from the pumps, and a possible heel impact of the SRAT receipt contents. Plot (c) shows that density first slowly dropped then began to rise for SRAT receipt batches in MB1b. 
Appendix A Exhibit A2 Plot (a) presents the Al concentration (wt \%) for SRAT receipt samples, the SRAT product samples, the SME samples, and the MFT samples. The measurements for elementals for the SRAT receipt samples were only available for a limited set of batches from MB1b. Since the SRAT product samples represent a more complete sequence for Al concentration than the SRAT receipt samples from MB1b, the Al concentration (wt \%) for only the SRAT product samples was reproduced in Plot (b). The Al concentration appears to drop until approximately SRAT batch 125, then begins a slow rise, staying in a range of about 2 to $4 \mathrm{wt} \%$ across MB1b. Plot (c) shows a similar pattern of change for Fe concentration (wt \%) in the SRAT product samples from MB1b, staying in range of 5 to $10 \mathrm{wt} \%$. The earliest batches of SRAT product may be affected by the SRAT heel.

Uniform mixing is the aim for individual process batches within DWPF. Clearly, the plots in the foregoing discussion did not display batch-to-batch uniformity across an entire macrobatch, so it can be inferred that mixing did not result in complete uniformly of the macrobatch contents in Tank $40 \mathrm{H}$ before transfers to the DWPF began. Nonetheless, the differences between process batches have not been so large as to affect glass production or glass product quality. 


\subsection{Waste Glass Chemical Composition and Uniformity}

Several studies have been designed and the data analyzed to support the analysis of the chemical composition in the glass product by Edwards [1994a, 1994b, 1995a, and 1995b]. These studies from the non-radioactive portion of the Startup Test program consisted of five campaigns during which approximately 90 canistered waste forms containing simulated waste glass were produced. The results of the pour stream samples were used to predict the composition of the glass in the canisters, and correlations between the pour stream and waste glass product were to be established.

The experimental design from the Edwards [1995a] report compared the following.

- Glass samples from the Melter Pour Stream.

- Glass samples from the filled canisters at the level of the pour stream sample by two methods

o Canisters that were sectioned. Twelve samples in total from each sectioned canister. Six canisters ( 3 early and 3 late) from each of the remaining campaigns were cut into 4 sections with the level of one cut corresponding to the level of the pour stream sample. A sample was obtained from each of the four radial locations on the top face of each of the bottom three sections.

o Canisters that had a wall removed. Three or more canisters had a wall, approximately 14" by 14 ", removed corresponding to the level of the pour stream sample. One sample was obtained from each of these canisters.

- Samples of batches of feed material were taken from the SME.

- Samples of batches of feed material were taken from the MFT.

All tanks are three-dimensional sampling structures, while a pour stream is a one-dimensional sampling structure. According to the Gy sampling theory, the difficulty of getting representative samples increases as the effective sampling dimension of the material increases. Consequently, sampling while the material is being transferred is generally an excellent way to obtain a sample since the effective dimension of the material is lower (maybe one-dimensional) than before the transfer. The sample from the pour stream was a grab sample, but it was matched with the canister (with the wall removed) sample and the sectioned canister samples at the associated fill height.

All samples were subjected to two types of dissolution, microwave and peroxide fusion, and analyzed for chemical composition for 19 elements, and were subjected to the PCT, an ASTM test method $^{5}$ for determining chemical durability of nuclear waste glasses. The preparations and the chemical analyses were portioned into separate blocks that could be run independently. All preparations and analyses within blocks were performed according to separate random orders. Replication of preparation and measurement tasks permitted a breakdown of variation by sampling, sample preparation, and measurement sources of variability.

\footnotetext{
${ }^{5}$ ASTM Standards, American Society of Testing and Materials, Test methods for Determining Chemical durability
} of Nuclear Waste Glasses: The Product Consistency Test (PCT), C-1285-94. 
This design typifies the framework of sampling studies to investigate glass composition and durability and to relate those factors to process samples. This study differs from tank mixing and sampling studies, as it was the waste glass product itself that was the focus of the experiment, and the glass product was subjected to systematic (spatial) sampling over its form, so that the uniformity of the glass product could be studied. 


\subsection{Selection of Pumping/Mixing/Transfer Methodology}

Two reports are discussed in this section. The first was an observational study (analysis of operations data) based on transfers from Tank $40 \mathrm{H}$ to the SRAT under different pumping conditions, and the second was a mixing study based on a designed experiment.

In the first study, Edwards [2008] documented a review of Tank 40H mixing conditions and SRAT product characteristics for sludge batch SB4. This study was based on transfers from Tank $40 \mathrm{H}$ in the Tank Farm to the SRAT in DWPF. This could be considered an observational study of Tank Farm operations since the study was not based on a designed experiment. However, this study demonstrates that the analysis of operating conditions can lead to greater insight into the factors that affect product quality.

The earliest set of transfers occurred before decanting Tank $40 \mathrm{H}$, while the later transfers were performed after the decantation. The objective of this analysis was to identify if there was an impact on the measured characteristics of the SRAT product that could be associated with the following.

- $\quad$ Number of pumps (three or four) used to mix Tank $40 \mathrm{H}$

- The specific combination of pumps if three pumps were used to transfer the material to the SRAT

- Duration (hours) of the mixing by the pumps.

The product characteristics studied included the following.

- Total Solids concentration (wt \%) in the SRAT product

- $\quad$ Predicted Total Solids concentration (wt \%) determined from additional bearing water being introduced into Tank $40 \mathrm{H}$ during mixing

- Al concentration (wt \%) as prepared by the cold chemical method and by the sodium peroxide fusion (fusion) method

- Fe concentration (wt \%)

- Na concentration (wt \%)

Results showed that there was a statistically significant difference in the average Al (fusion) concentration (wt \%) in the SRAT with a $0.67 \%$ increase when using three pumps instead of four pumps prior to the decantation. The average difference in the Total Solids concentration was statistically significant with the periods of three-pump operation lower than the four-pump periods of operation. However, the difference in Total Solids concentration was explained by the predicted Total Solids concentration due to the added bearing water. The Fe concentration (wt \%) was the only product characteristic that exhibited a statistically significant increase in variability with the three-pump operation.

After decant, none of the averages of any product characteristics displayed a statistically significant difference between the three-pump and the four-pump operation. The variability in the Al concentration (wt \%) was the only product characteristic that exhibited a statistically significant difference with the four-pump operation having a higher variability than the three-pump operation. 
Overall, there was little difference in the SRAT product characteristics between the three-pump operation and the four-pump operations. The variability of the SRAT product characteristics is a metric that can be used to study macrobatch variability. Additional transfers from Tank 40H were planned, and no quantitation of the product uniformity was published. The number of transfers in this study was insufficient to develop a variogram analysis of product characteristics over time. However, a study of an extended series of transfers from Tank $40 \mathrm{H}$ to the SRAT might reveal trends in the product characteristic averages of variabilities over time and provide insight into the mixing characteristics of Tank $40 \mathrm{H}$.

In the second report a mixing study for the Precipitator Hydrolysis Experimental Facility (PHEF) Tank was designed by Edwards [1992b] to be used as a general framework for conducting mixing studies. The objective was to study in-tank homogeneity by comparing grab samples taken from the top of the tank with samples obtained from a recirculation loop. The tank contents, the type of installed sampler, and the analytical tests were not documented in this report.

The initial test was to be conducted with the agitators on $30 \%$ power. Samples were to be collected from the recirculation loop after mixing times from 0 minutes to 240 minutes in increments of 15 minutes.

Additionally, grab samples were to be obtained with the agitators off. A grab sampler was to be lowered through a manhole in the top of the tank at the start of the mixing test (time 0 minutes), midway through the test (time 120 minutes) after the agitators were temporarily turned off, and after the completion of the test (time 240 minutes). Each sample was to be measured twice. Ten samples were to be obtained at each of these three times.

The experimental design was a basic approach to run the agitators as in production mode, but systematically obtain information at fixed time increments so that an appropriate mixing time could be established. The feature of in-tank grab sampling permitted a direct comparison with the samples obtained from the recirculation loop which was shown to be representative of the grab samples. 
SRNL-STI-2013-00544

Revision 0

\subsection{Conclusions}

The objective of this report was to present sampling methods that the SRS LWO used to study the DWPF process, not to present a list of outcomes from those studies. Representative sampling is important throughout the DWPF process, and the demonstrated success of the DWPF process to achieve glass product quality over the past two decades is a direct result of the quality of information obtained from the process. Numerous sampling studies were conducted during the development of the DWPF process and still continue in order to evaluate options for process improvement. Over the same time period, analytical methods for characterizing samples have been honed to assure consistent characterization effectiveness and to increase understanding of analytical uncertainties. Study designs were based on use of statistical tools applicable to the determination of uncertainties associated with the data needs. Successful designs are apt to be repeated, so this report chose only particular case studies that typify the characteristics of frequently used designs.

Case studies have been presented for studying in-tank homogeneity, evaluating the suitability of sampler systems, determining factors that affect mixing and sampling, comparing the final waste glass product chemical composition and durability to that of the important pour stream sample and other samples from process vessels, and assessing the uniformity of the waste glass product to chemical composition.

The time when many of these designs were implemented was in an age when the sampling ideas of Pierre Gy were not as widespread as they are today. Nonetheless, the engineers and statisticians used carefully thought out designs that systematically and economically provided plans for data collection from the DWPF process. Key shared features of the sampling designs used at DWPF and the Gy sampling methodology were the specification of a standard for sample representativeness, an investigation that produced data from the process to study the sampling function, and a decision framework used to assess whether the specification was met based on the data. Without going into detail with regard to the seven errors identified by Pierre Gy, as excellent summaries are readily available such as Pitard [1989] and Smith [2001], SRS engineers understood, for example, that samplers can be biased (Gy's extraction error), and developed plans to mitigate those biases. Experiments that compared installed samplers with more representative samples obtained directly from the tank may not have resulted in systematically partitioning sampling errors into the now well-known error categories of Gy, but did provide overall information on the suitability of sampling systems.

Most of the designs in this report are related to the DWPF vessels, not the large SRS Tank Farm tanks. Having the advantage of many years of processing that meets the waste glass product acceptance criteria, the DWPF process has provided a considerable amount of data about itself in addition to the data from many special studies. Demonstrating representative sampling directly from the large Tank Farm tanks is a difficult, if not unsolvable enterprise due to limited accessibility. However, the consistency and the adequacy of sampling and mixing at SRS could at least be studied under the controlled process conditions based on samples discussed by Ray and others [2012a] in WQR Volume 2 and the transfers from Tanks $40 \mathrm{H}$ and $51 \mathrm{H}$ to the SRAT within DWPF. It is important to realize that the need for sample 
representativeness becomes more stringent as the material gets closer to the melter, and the tanks within DWPF have been studied extensively to meet those needs.

The need for high quality process samples is greatest at the SME. Chemical composition measurements from SME process samples are input to the DWPF's Product Composition Control System (PCCS), a statistical process control system for monitoring SME batches and for supporting acceptability decisions at this production hold-point for DWPF. The PCCS strategy is to blend and then monitor the composition of the feed slurry in the SME, since the SME is the first control point at which all of the necessary constituents for the glass product are present and also the last control point at which any change to the constituents can be effected. 
SRNL-STI-2013-00544

Revision 0

\subsection{References}

[2007a] Analytical Laboratories (SRS). "Measuring and Calculating Sampling Uncertainty,” Administrative Procedure Manual L3.26, PCR 11589, Procedure L3.26.07041 (July 24).

[2007b] Analytical Laboratories (SRS). "Measuring and Calculating Method Uncertainty,” Administrative Procedure Manual L3.26, PCR 11710, Procedure L3.26.07031 (October 29).

[1984] Ator, R. A. “In-Tank Sludge Processing Demonstration Technical Summary,” DPSP-83-17-14, (September 13).

[2013] Cercy, M.J.; Peeler, D.K.; and Stone, M.E. "SRS Sludge Batch Qualification and Processing: Historical Perspective and Lessons Learned,” SRNL-STI-2013-00585, (September).

[1981] Churnetski, B.V. “Effective Cleaning Radius Studies,” DPST-81-282 (February 19).

[1979] Comly, C. “Tank 16 Demonstration Multipump Test Results”, DPSP-79-17-17 (June 29).

[1992a] Edwards, T.B. "Statistical Design for the MFT Homogeneity Study at TNX," Westinghouse Inter-Office Memorandum SCS-ASG-92058 (August 27).

[1992b] Edwards, T.B. “Experimental Design for PHEF Tank Mixing Test,” Westinghouse Savannah River Company Inter-Office Memorandum SCS-ASG-92090 (December 28).

[1992c] Edwards, T.B. “Task Plan for Test of PRBT Prototypic Liquid Sampler Rev. 1 (U),” Westinghouse Savannah River Company Inter-Office Memorandum WSRC-RP-90-1055, Rev. 1 (February 3).

[1994a] Edwards, T.B. "Statistical Design for the Modified FA-10.02 Extended Testing at the DWPF (U),” Westinghouse Savannah River Company Inter-Office Memorandum SCS-ASG-940005 (January 25).

[1994b] Edwards, T.B. "Statistical Design for the Settling Test Phase of the Modified FA-10.02 Extended Testing at the DWPF (U),” Westinghouse Savannah River Company Inter-Office Memorandum SCS-ASG-940025 (March 28).

[1995a] Edwards, T.B. "Statistical Design for Analyses of Chemical Composition of WP14 Glass Samples (U),” Westinghouse Savannah River Company Inter-Office Memorandum SCS-ASG-95-0022 (March 20).

[1995b] Edwards, T.B., "Statistical Analyses of Chemical Composition and Durability Data from the DWPF’s Startup Test program (U),” SRT-ASG-940070 (February 17). 
[2000] Edwards, T. B. "Statistical Review of Composition Data from DWPF's Process Samples for Macro-Batch 1 and Macro-Batch 2 (U),” WSRC-RP-2000-00174, Revision 0 (February 15).

[2003] Edwards, T.B. “A Statistical Review of Analytical Laboratory Measurements from DWPF’s Macrobatch 1 and Macrobatch 2 (U),” WSRC-TR-2003-00045, Revision 0 (January 22).

[2006] Edwards, T.B. "SME Acceptability Determination for DWPF Process Control (U),” WSCR-TR-95-000364, Revision 5 (September 2006).

[2008] Edwards, T.B. “A Statistical Review of Tank 40 Mixing Conditions and SRAT Product Characteristics for SB4,” SRNL Inter-office Memorandum SRNL-SCS-2008-00070 (June 30).

[2009] Edwards, T.B. "Statistical Support for Planning the SME Viability Testing of the Isolok," SRNL-L5200-2009-00022 (June 5).

[2010] Edwards, T.B. "Statistical Support for Planning the Next Phase of SME Viability Testing of the Isolok,” SRNL-L5200-2010-00025 (June 11).

[2010a] Harris, S. P. "Statistical Analysis of Tank 18F Floor Sample Results," SRNL-STI-2010-00401 (September).

[2010b] Harris, S. P. "Statistical Analysis of Tank 19F Floor Sample Results," SRNL-STI-2010-00400 (September).

[1979] Gy, P.M. Sampling of Particulate Materials, Elsevier, Amsterdam.

[2011] Hera, K.R.; Coleman, C.J.; Edwards, T.B. “Isolok Valve Viability Testing for DWPF SME Sampling Process,” SRNL-STI-2010-00749, Rev. 0 (January).

[1992] Jenkins, W.J. “Task Plan for Test of PRBT Prototypic Liquid Sampler, Rev. 1,” WSRC-RP-90-1055, Rev. 1 (February 3).

[1984] Motyka, T. “Technical Data Summary for In-Tank Sludge Processing”, DPSTD-84-100 (April).

[2008] Nash, C.A.; Peters, T.B.; and Fink, S.D., “Tank 49H Salt Batch Supernate Qualification for ARP/MCU”, WSRC-STI-2008-00117 (August 25).

[1996] Office of Environmental Management, "Waste Acceptance Product Specifications for Vitrified High-Level Waste Forms, Revision 2, USDOE Document EM-WAPS, U.S. Department of Energy, Germantown, MD.

[2013] Oji, L. N., D. P. DiPrete, C. J. Coleman, M. S. Hay, and E. P. Shine, "Analysis of the Tank 6F Final Characterization Samples -- 2012," SRNL-STI-2012-00365, Rev. 2 (January).

[1989] Pitard, F.F. Pierre Gy’s Sampling Theory and Sampling Practice: Volume 1 Heterogeneity and Sampling and Volume II Sampling Correctness and Sampling Practice, CRC press, Inc., Boca Raton, FL. 
[1995] Poirier, M.R. “Slurry Pump Operation in Tank 48 (U),” Westinghouse Savannah River Company Report WSRC-RP-94-01223, Rev. 1 (March 9).

[2004] Poirier, M.R. "Mixing in SRS Closure Business Unit Applications,” Washington Savannah River Company Report WSRC-TR-2004-00153, Rev. 0 (March 30).

[2012a] Ray, J.W., Staub, A.V., Marra, S.L., Coleman, C.J., and Plodinec, M.J. "Reporting the Chemical Composition of the DWPF Product (U),” WSRC-IM-91-116-2, Revision 5 (June).

[2012b] Ray, J.W., Culbertson, B.H., Marra, S.L., and Plodinec, M.J. “The DWPF Glass Product Control Program (U), WSRC-IM-91-116-6, Revision 7 (June).

[2013] Reboul, S.H.; Cercy, M.J.; Shine, E.P.; and Young, J.E. “Task Technical and Quality Assurance Plan for Hanford Waste Treatment and Immobilization Plant (WTP) Feed Acceptance and Qualification Support,” SRNL-RP-2013-00310 (June).

[2010] Savannah River Site, “Concentration, Storage, and Transfer Facilities,” S-TSR-G-00001, Rev. 26, (March 2010).

[2010] Shine, E. P. "Statistical Analysis of Tank 5 Floor Sample Results," SRNL-STI-2011-00613, Rev. 2 (January).

[2013] Shine, E. P. "analysis of Sampling Plan Options for Tank 16H," SRNL-STI-2011-00100, (February).

[2001] Smith, P.L. A Primer for Sampling Solids, Liquids, and Gases Based on the Seven Sampling Errors of Pierre Gy, SIAM, Philadelphia, PA. 


\section{Appendix A}

Table A1. Components of Variance for SRAT Receipt from MB2

(Edwards, WSRC-TR-2003-00045, Table 5)

\begin{tabular}{|c|c|c|c|c|c|c|c|c|c|c|c|c|c|}
\hline & & $\%$ & Compones & ff Variation & Var & nce Compo & ents & \%RSD & \%RSD & \%RSD & Mean & Degrees of & \\
\hline Analyte & Mean & S. E. Mean & Batch & Residual & Total & Batch & Residual & Total & Batch & Residual & Squares & Freedom & $\mathbf{N}$ \\
\hline Total Solids (wt \%) & 14.890 & $0.8 \%$ & $94.7 \%$ & $5.3 \%$ & 1.706 & 1.615926 & 0.090218 & $8.8 \%$ & $8.5 \%$ & $2.0 \%$ & 9.01132 & 114 & 635 \\
\hline Calcine Solids (wt \%) & 12.668 & $0.8 \%$ & $82.2 \%$ & $17.8 \%$ & 0.771 & 0.633696 & 0.137142 & $6.9 \%$ & $6.3 \%$ & $2.9 \%$ & 3.50671 & 71 & 383 \\
\hline Insoluble Solids (wt \%) & NA & NA & NA & NA & $\mathrm{NA}$ & NA & NA & $\mathrm{NA}$ & $\mathrm{NA}$ & $\mathrm{NA}$ & $\mathrm{NA}$ & NA & NA \\
\hline Density $(\mathrm{g} / \mathrm{mL})$ & 1.083 & $0.1 \%$ & $57.4 \%$ & $42.6 \%$ & 0.000 & 0.000202 & 0.00015 & $1.7 \%$ & $1.3 \%$ & $1.1 \%$ & 0.00096 & 114 & 460 \\
\hline Total Hydroxide (eq/L) & 0.112 & $1.9 \%$ & $100.0 \%$ & $0.0 \%$ & 0.0005 & 0.000495 & 0 & $19.9 \%$ & $19.9 \%$ & $0.0 \%$ & 0.000495 & 113 & $\overline{114}$ \\
\hline Formate (ppm) & 4397.5 & $1.8 \%$ & $98.2 \%$ & $1.8 \%$ & 751886.8 & 738698.7 & 13188.12 & $19.7 \%$ & $19.5 \%$ & $2.6 \%$ & 2967983 & 114 & 460 \\
\hline Chloride (ppm) & NA & NA & NA & NA & NA & NA & NA & NA & NA & NA & NA & NA & NA \\
\hline Fluoride (ppm) & NA & NA & NA & NA & NA & NA & NA & NA & NA & $\mathrm{NA}$ & NA & NA & NA \\
\hline Nitrate (ppm) & 5059.8 & $2.0 \%$ & $97.5 \%$ & $2.5 \%$ & 1141200.6 & 1112659 & 28541.59 & $21.1 \%$ & $20.8 \%$ & $3.3 \%$ & $4.48 \mathrm{E}+06$ & 114 & 460 \\
\hline Nitrite (ppm) & 4795.0 & $1.1 \%$ & $97.7 \%$ & $2.3 \%$ & 328250.0 & 320618.8 & 7631.232 & $11.9 \%$ & $11.8 \%$ & $1.8 \%$ & 1290106 & 114 & 460 \\
\hline Sulfate (ppm) & 1077.5 & $1.1 \%$ & $3.6 \%$ & $96.4 \%$ & 56177.2 & 2050.275 & 54126.9 & $22.0 \%$ & $4.2 \%$ & $21.6 \%$ & 62328 & 114 & 460 \\
\hline Aluminum (wt \%) & 8.157 & $2.7 \%$ & $84.7 \%$ & $15.3 \%$ & 0.621 & 0.525936 & 0.095069 & $9.7 \%$ & $8.9 \%$ & $3.8 \%$ & 2.90838 & 10 & 59 \\
\hline Boron (wt \%) & 0.015 & $64.4 \%$ & $64.3 \%$ & $35.7 \%$ & 0.001 & 0.000959 & 0.000533 & $254.1 \%$ & $203.7 \%$ & $151.9 \%$ & 0.00566 & 10 & 59 \\
\hline Calcium (wt \%) & 2.465 & $2.7 \%$ & $85.0 \%$ & $15.0 \%$ & 0.054 & 0.045859 & 0.00808 & $9.4 \%$ & $8.7 \%$ & $3.6 \%$ & 0.25338 & 10 & 59 \\
\hline Chromium (wt \%) & 0.150 & $1.8 \%$ & $34.3 \%$ & $65.7 \%$ & 0.000 & 0.000061 & 0.000117 & $8.9 \%$ & $5.2 \%$ & $7.2 \%$ & 0.00045 & 10 & 59 \\
\hline Copper (wt \%) & 0.042 & $3.1 \%$ & $59.3 \%$ & $40.7 \%$ & 0.000 & 0.000016 & 0.000011 & $12.3 \%$ & $9.5 \%$ & $7.8 \%$ & 0.0001 & 10 & 59 \\
\hline Iron (wt \%) & 22.559 & $2.1 \%$ & $75.9 \%$ & $24.1 \%$ & 2.993 & 2.272166 & 0.720512 & $7.7 \%$ & $6.7 \%$ & $3.8 \%$ & 12.8747 & 10 & 59 \\
\hline Potassium (wt \%) & 0.233 & $13.0 \%$ & $62.1 \%$ & $37.9 \%$ & 0.015 & 0.009091 & 0.00556 & $51.9 \%$ & $40.9 \%$ & $32.0 \%$ & 0.05419 & 10 & 59 \\
\hline Lithium (wt \%) & 0.010 & $8.3 \%$ & $37.5 \%$ & $62.5 \%$ & 0.000 & 0.000006 & 0.00001 & $40.2 \%$ & $24.6 \%$ & $31.8 \%$ & 0.00004 & 10 & 59 \\
\hline Magnesium (wt \%) & 1.212 & $2.4 \%$ & $81.1 \%$ & $18.9 \%$ & 0.011 & 0.009057 & 0.002111 & $8.7 \%$ & $7.8 \%$ & $3.8 \%$ & 0.05056 & 10 & 59 \\
\hline Manganese (wt \%) & 3.473 & $3.1 \%$ & $87.4 \%$ & $12.6 \%$ & 0.140 & 0.122724 & 0.017644 & $10.8 \%$ & $10.1 \%$ & $3.8 \%$ & 0.67412 & 10 & 59 \\
\hline Sodium (wt \%) & 7.529 & $7.1 \%$ & $2.7 \%$ & $97.3 \%$ & 14.863 & 0.407276 & 14.45597 & $51.2 \%$ & $8.5 \%$ & $50.5 \%$ & 16.6346 & 10 & 59 \\
\hline Nickel (wt \%) & 0.338 & $2.0 \%$ & $41.1 \%$ & $58.9 \%$ & 0.001 & 0.000404 & 0.000579 & $9.3 \%$ & $5.9 \%$ & $7.1 \%$ & 0.00274 & 10 & 59 \\
\hline Silicon (wt \%) & 1.059 & $12.7 \%$ & $92.4 \%$ & $7.6 \%$ & 0.214 & 0.197572 & 0.016323 & $43.7 \%$ & $42.0 \%$ & $12.1 \%$ & 1.07317 & 10 & 59 \\
\hline Titanium (wt \%) & 0.021 & $4.9 \%$ & $80.0 \%$ & $20.0 \%$ & 0.000 & 0.000012 & 0.000003 & $18.6 \%$ & $16.7 \%$ & $8.3 \%$ & 0.00006 & 10 & 59 \\
\hline Uranium (wt \%) & 3.307 & $2.4 \%$ & $62.2 \%$ & $37.8 \%$ & 0.101 & 0.062927 & 0.03827 & $9.6 \%$ & $7.6 \%$ & $5.9 \%$ & 0.37488 & 10 & 59 \\
\hline Zirconium (wt \%) & 0.063 & $4.7 \%$ & $89.6 \%$ & $10.4 \%$ & 0.000 & 0.000095 & 0.000011 & $16.4 \%$ & $15.5 \%$ & $5.3 \%$ & 0.00052 & 10 & 59 \\
\hline
\end{tabular}




\section{Appendix A}

Table A1 Continued. Components of Variance for SRAT Receipt from MB2

\begin{tabular}{|c|c|c|c|c|c|c|c|c|c|c|c|c|c|}
\hline & & $\%$ & Componen & f Variation & Var & nce Compo & ents & \%RSD & \%RSD & \%RSD & Mean & Degrees of & \\
\hline Analyte & Mean & S. E. Mean & Batch & Residual & Total & Batch & Residual & Total & Batch & Residual & Squares & Freedom & $\mathbf{N}$ \\
\hline TIC (ppm) & 767.253 & $2.0 \%$ & $96.1 \%$ & $3.9 \%$ & 28405.983 & 27301.98 & 1104.003 & $22.0 \%$ & $21.5 \%$ & $4.3 \%$ & 109831 & 113 & 454 \\
\hline TOC (ppm) & NA & NA & NA & NA & NA & NA & NA & NA & NA & NA & NA & NA & NA \\
\hline $\mathrm{Fe} / \mathrm{Al}$ & 2.773 & $1.2 \%$ & $95.6 \%$ & $4.4 \%$ & 0.012 & 0.01194 & 0.000555 & $4.0 \%$ & $3.9 \%$ & $0.8 \%$ & 0.06443 & 10 & 59 \\
\hline $\mathrm{Fe} / \mathrm{Ca}$ & 9.175 & $1.5 \%$ & $84.9 \%$ & $15.1 \%$ & 0.254 & 0.215527 & 0.038318 & $5.5 \%$ & $5.1 \%$ & $2.1 \%$ & 1.19121 & 10 & 59 \\
\hline $\mathbf{F e} / \mathbf{L i}$ & 2647.200 & $10.7 \%$ & $54.4 \%$ & $45.6 \%$ & 1420080 & 772020.2 & 648059.5 & $45.0 \%$ & $33.2 \%$ & $30.4 \%$ & 4777713 & 10 & 59 \\
\hline $\mathbf{F e} / \mathbf{M n}$ & 6.529 & $4.2 \%$ & $99.8 \%$ & $0.2 \%$ & 0.165 & 0.164444 & 0.000383 & $6.2 \%$ & $6.2 \%$ & $0.3 \%$ & 0.88002 & 10 & 59 \\
\hline Mercury (ppm) & 1222.545 & $6.3 \%$ & $100.0 \%$ & $0.0 \%$ & 65267.270 & 65267.27 & 0 & $20.9 \%$ & $20.9 \%$ & $0.0 \%$ & 65267.3 & 10 & 11 \\
\hline
\end{tabular}




\section{Appendix A}

Exhibit A1. Components of Variance for SRAT Receipt Batches from MB1b

(Edwards, WSRC-TR-2003-00045, Exhibit A3)

Plot (a). Total Solids (wt \%) by SRAT Receipt Batches

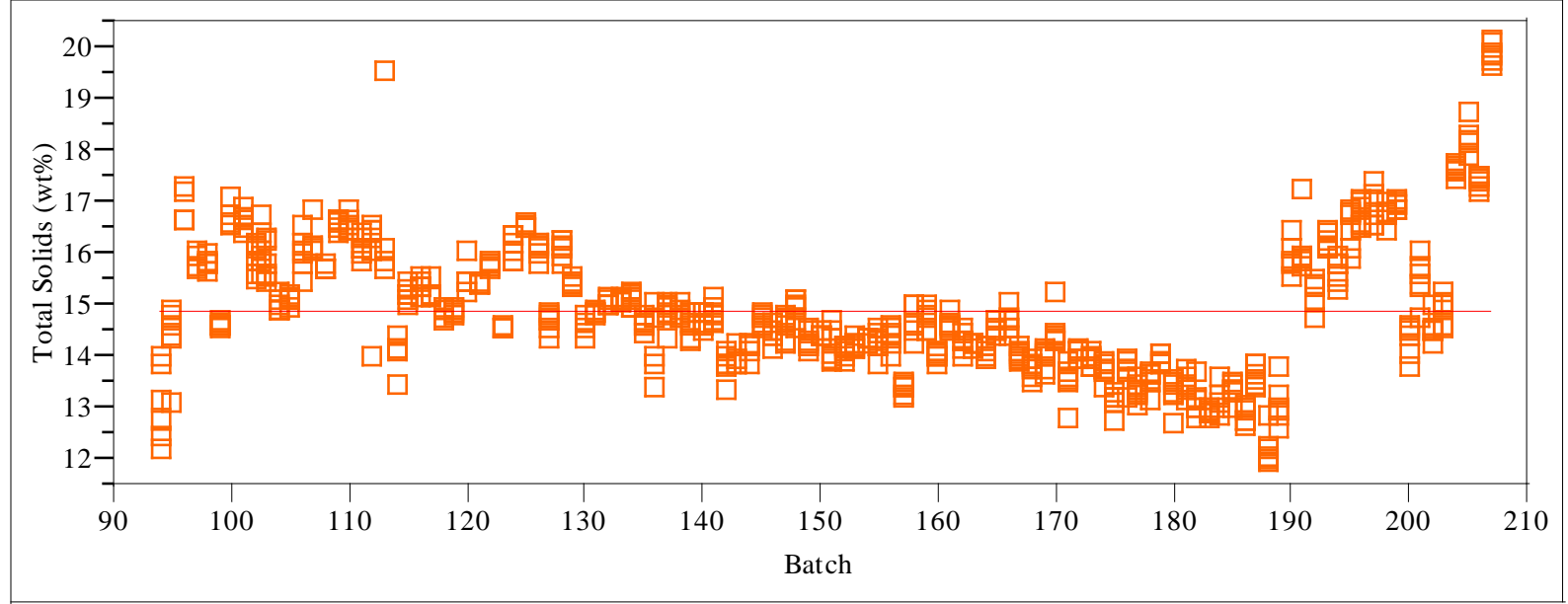

Plot (b). Calcined Solids (wt \%) by SRAT Receipt Batches

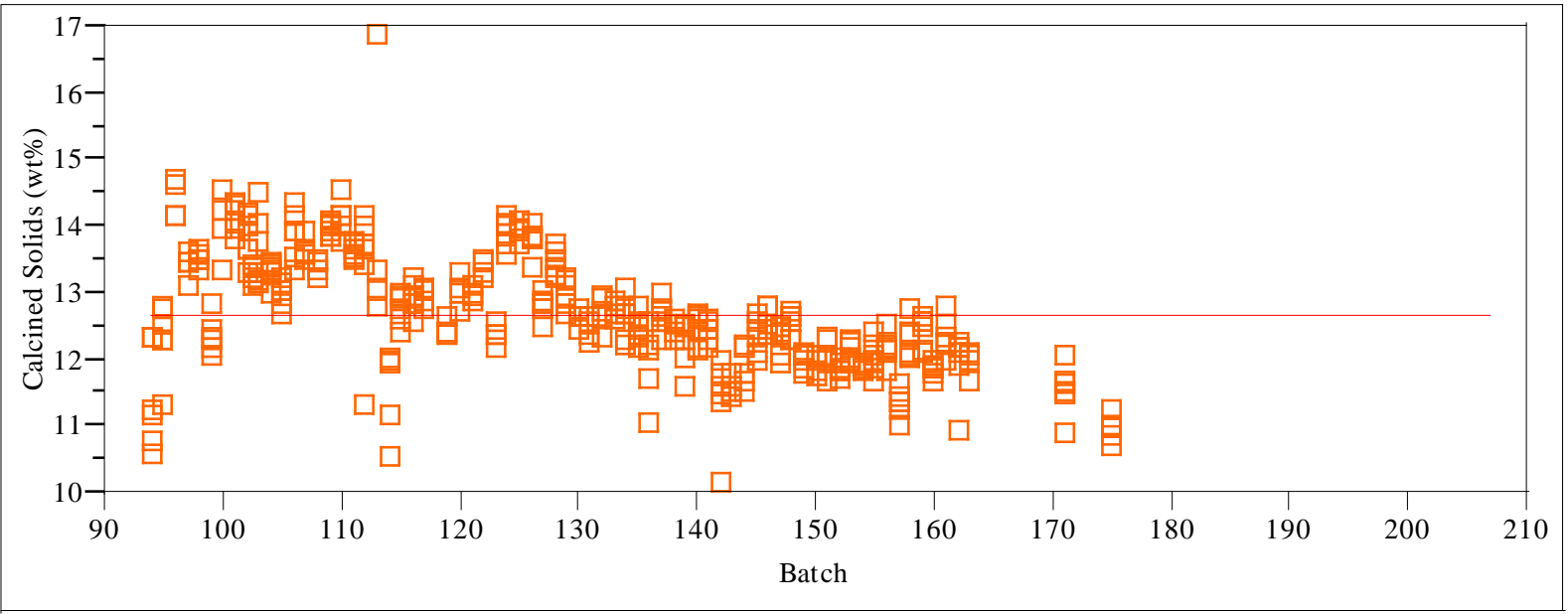




\section{Appendix A}

Exhibit A1 Continued. Components of Variance for SRAT Receipt Batches from MB1b

Plot (c). Density (g/mL) by SRAT Receipt Batches

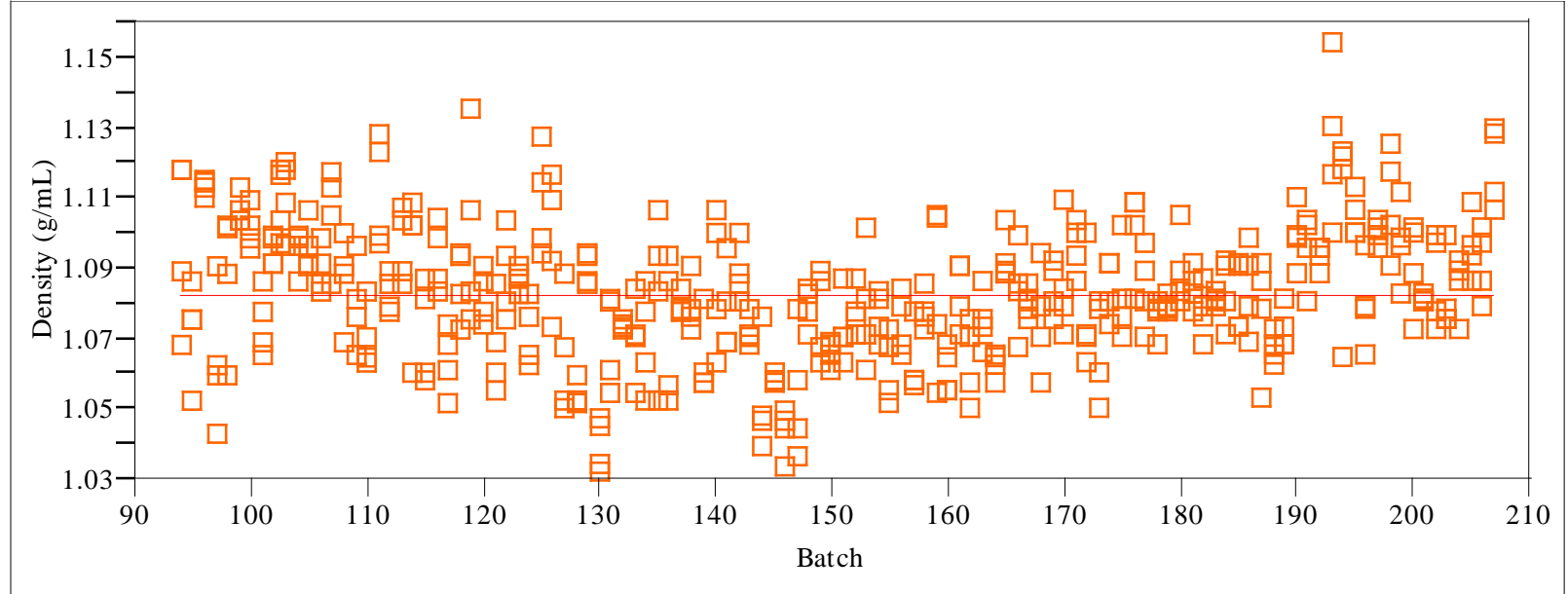




\section{Appendix A}

Exhibit A2. Components of Variance for Aluminum and Iron from MB1b

Plot (a). Aluminum (wt \%) by Process Batches at SRAT Receipt, SRAT Product, SME, and MFT

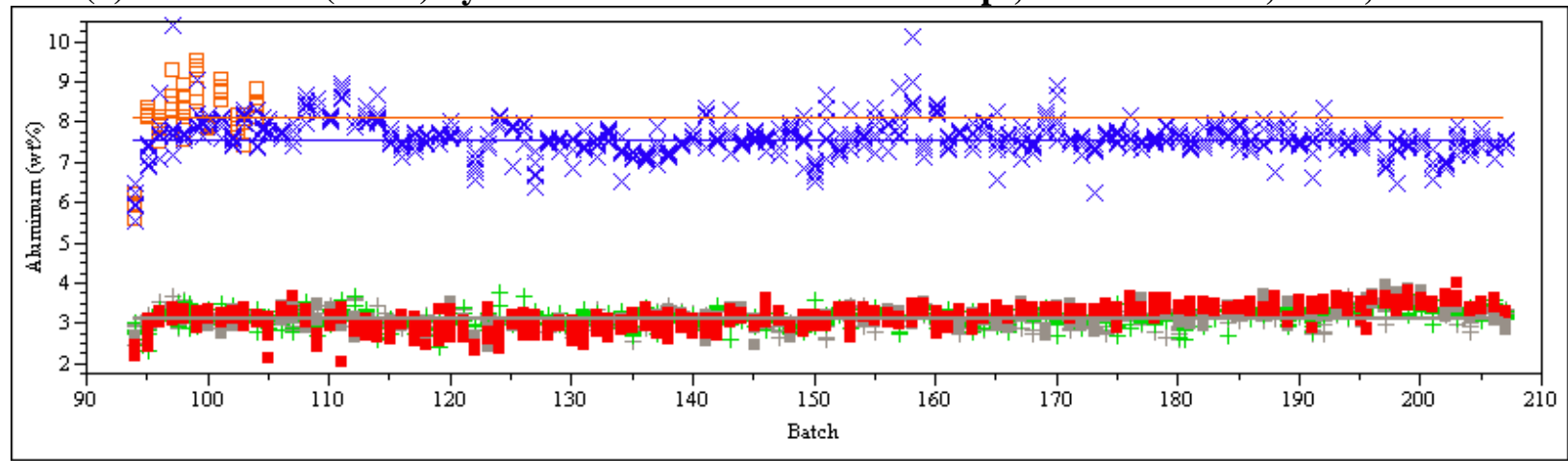

Legend: (Open Orange Square - SRAT Receipt; Blue “X” - SRAT Product; Small Red Square - SME (lighter color F prep); Green “+” - MFT (lighter color F prep)

\section{Plot (b). Aluminum (wt \%) by SRAT Product Batches}

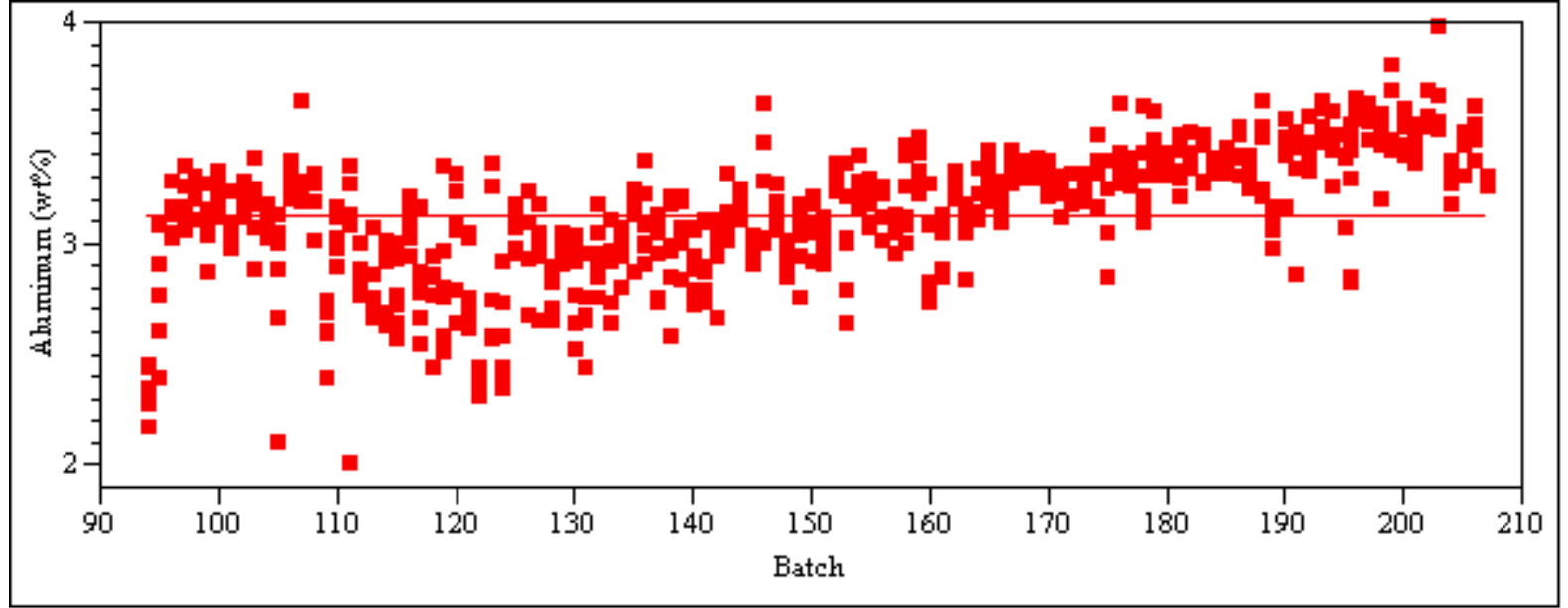




\section{Appendix A}

Exhibit A2 Continued. Components of Variance for Aluminum and Iron from MB1b

Plot (c). Iron (wt \%) by SRAT Product Batches

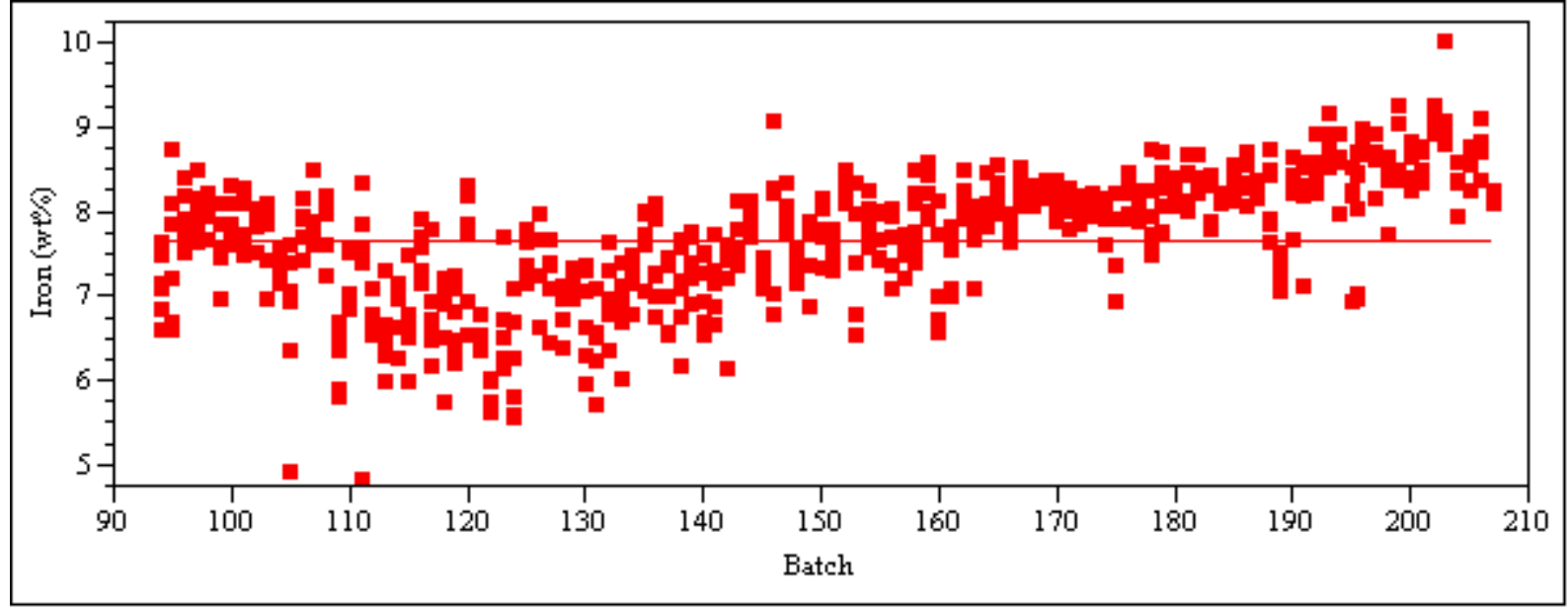


SRNL-STI-2013-00544

Revision 0

This Page Left Intentionally Blank 


\section{Distribution:}

SRNL

D. J. Adamson, 999-W

T. B. Brown, 773-A

M. J. Cercy, 773-42A

D. R. Click, 999-W

T. B. Edwards, 999-W

S. D. Fink, 773-A

E. K. Hansen, 999-W

C. C. Herman, 773-A

E. N. Hoffman, 999-W

M.K. Harris, 703-41A

S. L. Marra, 773-A

D. K. Peeler, 999-W

J. R. Pelfrey, 773-42A

F. M. Pennebaker, 773-42A

M. R. Poirier, 773-42A

S. H. Reboul, 773-42A

M. E. Stone, 999-W

W. R. Wilmarth, 773-A

Records Administration (EDWS)

$\underline{\text { SRR }}$

J. M. Bricker, 704-30S

J. W. Ray, 704-S

K. H. Subramanian, 241-156H

DOE-SR

P. R. Jackson, 703-46A
WTP

A. V. Arakali

S. M. Barnes

P. A. Benson

G. M. Duncan

M. R. Hamlet

J. Markillie

J. L. Nelson

I. G. Papp

WRPS

S. T. Arm

T. W. Crawford

W. G. Ramsey

J. G. Reynolds

P. L. Rutland

S. A. Saunders

D. H. Shuford

M. G. Thien

L. E. Thompson

PNNL

R. D. Peterson

DOE-ORP

D. H. Alexander

J. A. Diediker

T. W. Fletcher

B. J. Harp

C. C. Harrington

A. A. Kruger

I. Wheeler

W. R. Wrzesinski 